Illinois State University

ISU ReD: Research and eData

Theses and Dissertations

6-12-2017

\title{
"They ate macaroni-and-cheese or TV dinners; my mother made curry instead": A narrative inquiry of South Asian American writers' identity negotiation
}

Su Yin Khor

Illinois State University, sykhor30@gmail.com

Follow this and additional works at: https://ir.library.illinoisstate.edu/etd

Part of the Bilingual, Multilingual, and Multicultural Education Commons, and the Linguistics Commons

\section{Recommended Citation}

Khor, Su Yin, "'They ate macaroni-and-cheese or TV dinners; my mother made curry instead": A narrative inquiry of South Asian American writers' identity negotiation" (2017). Theses and Dissertations. 759. https://ir.library.illinoisstate.edu/etd/759

This Thesis is brought to you for free and open access by ISU ReD: Research and eData. It has been accepted for inclusion in Theses and Dissertations by an authorized administrator of ISU ReD: Research and eData. For more information, please contact ISUReD@ilstu.edu. 
“THEY ATE MACARONI-AND-CHEESE OR TV DINNERS; MY MOTHER MADE CURRY

INSTEAD": A NARRATIVE INQUIRY OF SOUTH ASIAN AMERICAN WRITERS'

IDENTITY NEGOTIATION

Su Yin Khor

\section{Pages}

As the demographic and linguistic landscape in the United States is shifting - the Asian population has increased significantly in the last decade, particularly the South Asian population - these changes are reflected in the classrooms all over the country. As such, it becomes imperative to investigate who these multilinguals are, and as several scholars have pointed out, the Asian population has not been studied to the same extent as other minorities. In addition, the notion of a homogenous Asian identity persists and hides the internal differences that exist within the Asian population.

Therefore, the aim of this thesis was to challenge the notion of a homogenous Asian identity by exploring the identity struggles and identity negotiation of South Asian Americans. To understand their identity struggles and negotiation processes, a post-structural perspective was adopted and narrative inquiry was employed to broaden the range of methodologies that are used to research multilingual identities. A corpus consisting of memoirs and short narratives written by South Asian Americans was created and analyzed.

From the analysis of the narratives, four themes emerged: Theme 1: Indexing the "Other," Theme 2: Labels and self-identification, Theme 3: Positioning of self and others, and Theme 4: Linguistic identities. Theme 1 concerns the ways in which the writers were "othered," 
mainly through physical attributes, their names, and cultural practices that they engaged in that were not seen as American. Theme 2 shows that the writers mainly identified and referred to themselves through their ethnic heritage, and Theme 3 reveals that the writers commonly positioned themselves as outsiders and different from the white American. Lastly, Theme 4 highlights the writers' complicated relationship with English and that a standard language ideology persists.

Echoing previous research, the findings of this study suggest that the construction and negotiation of multilingual identities are very much linked to larger societal issues grounded in a limited view of what it means to be American, pervasive language ideologies that promote Standard English varieties, as well as the persisting notion of a singular Asian identity. Additionally, employing narrative inquiry has opened up for additional possibilities to study multilingual identities, which I suggest should be explored further to expand on identity research that is currently conducted in applied linguistics and related fields.

KEYWORDS: Identity negotiation; Narrative inquiry; Asian; South Asians; Memoirs; Narratives 
“THEY ATE MACARONI-AND-CHEESE OR TV DINNERS; MY MOTHER MADE CURRY INSTEAD”: A NARRATIVE INQUIRY OF SOUTH ASIAN AMERICAN WRITERS'

IDENTITY NEGOTIATION

SU YIN KHOR

A Thesis Submitted in Partial Fulfillment of the Requirements for the Degree of

MASTER OF ARTS

Department of English

ILLINOIS STATE UNIVERSITY

2017 
(C) $2017 \mathrm{Su}$ Yin Khor 
“THEY ATE MACARONI-AND-CHEESE OR TV DINNERS; MY MOTHER MADE CURRY INSTEAD”: A NARRATIVE INQUIRY OF SOUTH ASIAN AMERICAN WRITERS' IDENTITY NEGOTIATION

SU YIN KHOR

COMMITTEE MEMBERS:

Lisya Seloni, Chair

K. Aaron Smith 


\section{ACKNOWLEDGMENTS}

The title of this thesis comes from Carmit Delman's memoir Burnt bread and chutney:

Growing up between cultures-A memoir of an Indian Jewish girl, one of the memoirs that I read for my thesis. Just like Delman, I grew up in-between cultures: my mother made Malaysian fried rice, while my friends ate macaroni and meatballs with ketchup, a common Swedish dish. For a very long time, I struggled with reconciling the contradictory identities that I claimed. I still struggle sometimes, but now I know that I can be Asian and European, as well as Malaysian, Chinese, and Swedish - I do not have to choose or give up any of these identities. Who knew that, one day, a thesis would emerge from my own identity journey?

Of course, my identity has not been constructed in a vacuum, so I want to use this space to thank the people who have supported me and shaped me as an emerging scholar and a citizen of the world. First, there would be no thesis without the support and guidance from my committee, Dr. Lisya Seloni and Dr. K. Aaron Smith: I hope that when it is my turn to advise students, I will be able to guide them the way that you have guided me: with passion, patience and wit. Thank you for supporting my work and my scholarly journey. Jag är evigt tacksam. (I am forever grateful.)

I would also like to thank my friends and (ridiculous) cohort for all the hugs, academic conversations, but also the office shenanigans (which should remain classified). I specifically want to thank Katy Lewis for never complaining about the gum wrappers that I leave everywhere in our office and for helping me make sense of my thoughts_사랑해; William Hanley for challenging me intellectually and for getting me donuts (junk) food during late night writing sessions; Daniel Engle for always being there for me and cheering on me since day oneironically enough, I am struggling to find words (!) that can express how grateful I am and how 
much you have influenced me; to my beloved friends at home, Josefin Wred and Katrin Friberg, I apologize for waking you up in the middle of the night with my texts (and silly voice messages) and for missing phone calls, and Dr. James Stanlaw for always listening to my thoughts and ideas, no matter if they are wrong or plain ridiculous (or both).

Although there are so many people I want to thank-my department, professors, friends, coworkers, acquaintances, and baristas that provide me with coffee-there is not enough space for me to do so, but you should know that no matter what our relationship is, you did something to shape my identity. For that, I thank you.

Lastly, I would like to thank my family for always supporting my intellectual and professional endeavors. Thank you, mom and dad, for teaching me that I could be whoever I wanted to be, and that, at the end of the day, it does not matter what people think of me. You two are the most hardworking, dedicated, and disciplined people I have ever met, and I only hope to be half as good as you are. My (not so) little brother, thank you for amusing me with the pictures of all the food that you make. What is your next food experiment?

To everyone that I have mentioned here on these pages, and everyone that I have crossed paths with, know that I will carry you with me no matter where I end up in life. Kam Siah!

S. K. 


\section{CONTENTS}

\section{Page}

ACKNOWLEDGMENTS

CONTENTS

iii

TABLES

vi

CHAPTER I: THE PROBLEM AND ITS BACKGROUND

The changing demographics in American education

$\begin{array}{ll}\text { Statement of the problem } & 4\end{array}$

$\begin{array}{ll}\text { Research questions } & 7\end{array}$

Methodology: Narrative inquiry, data selection, and analysis $\quad 8$

$\begin{array}{ll}\text { Overview of essential terms } & 13\end{array}$

Contesting the "Asian" identity 13

Race, ethnicity, and culture $\quad 14$

Defining first generation immigrant, 1.5 generation, and second generation immigrant 17

$\begin{array}{ll}\text { Organization of the thesis and chapter descriptions } & 18\end{array}$

CHAPTER II: THEORETICAL FRAMEWORK AND LITERATURE REVIEW 19

Part I: Theoretical framework $\quad 19$

$\begin{array}{ll}\text { A post-structuralist perspective on identity } & 19\end{array}$

$\begin{array}{ll}\text { Part II: Literature review } & 25\end{array}$

The intersections of language, identity, race, and culture 25

$\begin{array}{ll}\text { Struggling for legitimacy } & 26\end{array}$

The "homogenous Asian identity" 31 
Contradictory images of Asian Americans: "The model minority" and "the perpetual

foreigner"

“How do you say your name?": Naming rights

CHAPTER III: RESEARCH METHODOLOGY

Using narrative inquiry to investigate multilingual identities

Data selection: Memoirs and short narratives

Data analysis: Unpacking the narratives

Researcher positionality

Methodological limitations

Chapter summary

Overarching themes in the narratives

Part I: Analysis of contents

Theme 1: Indexing the "other"

Physical attributes as markers of "otherness."

The relationship between names and identities.

Being (un)American.

Summary of Part I

Part II: The construction of identities within the narratives

Theme 2: Labels and self-identification

Theme 3: Positioning of self and others

Theme 4: Linguistic identities 
$\begin{array}{ll}\text { CHAPTER V: CONCLUSION } & 91\end{array}$

Summarizing the study and its goals $\quad 91$

Revisiting research question 1: Identity struggles 994

Revisiting research question 2: Themes and commonalities 97

Revisiting research question 3: Identifying with the "Asian” identity 101

Limitations of the study and future research 102

$\begin{array}{ll}\text { Concluding comments } & 103\end{array}$

$\begin{array}{lr}\text { REFERENCES } & 106\end{array}$ 


\section{TABLES}

Table

1. Overview of selected memoirs and short narratives

2. The selection of memoirs and narratives 


\section{CHAPTER I: THE PROBLEM AND ITS BACKGROUND}

\section{The changing demographics in American education}

The educational demographics in the United States is currently going through a shift: projections made by the National Center for Educational Statistics (2017) show that Hispanic, Black, Asian or Pacific Islander students are estimated to make up the majority in public K-12 classrooms by 2017. These groups of students are expected to increase steadily in the near future as well. In fact, the Asian population has grown more than any other group in the United States since the last census (U.S. Census Bureau, 2012). In other words, minorities will make up the majority of the student population in classrooms all over the country, including K-12 and higher education, and in some schools, this shift has already occurred. In light of these demographic developments, it becomes increasingly important to study the linguistic and sociocultural profiles of individuals of Asian origin in the United States, as these changes have several pedagogical implications: they alter the educational demographics, with students bringing various linguistic and cultural resources to the classrooms in both $\mathrm{K}-12$ and higher education.

As stated, the presence of students of Asian origin ${ }^{1}$ will be much greater than it has been in the past. The 2010 Census shows that the Asian population grew faster than any other group between 2000 and 2010, with the largest groups being Chinese, Indians, and Filipinos. The Asian population experienced a growth from 10.2 million to 14.7 million-increasing four times faster than the total U.S. population — and grew significantly in every state (except for Hawaii), with at least a 30 percent increase (U.S. Census Bureau, 2012). Data from 2016, gathered by the Institute of International Education, also reflects these demographic changes: $60 \%$ of international

\footnotetext{
1 "Asian" and other terms are defined later in this chapter.
} 
students came from China, India, Saudi Arabia, and South Korea. A high number of students from other Asian countries also entered the United States, such as Vietnam, Taiwan, and Japan.

Alongside the demographic changes, the use of Asian languages in the United States has also increased since the 1980s, particularly with South Asian languages experiencing a high level of growth: Hindi grew by 105 percent and "Other Asian Languages," i.e. Dravidian languages, such as Tamil, Telugu, and Malayalam, grew by 115 percent. It is also necessary to be aware of the fact that within the South Asian population, English is not the only language spoken at home. Out of those who reported that they spoke other languages than English at home, 1.1 percent reported that they spoke Hindi, 0.6 percent spoke Gujarati and Urdu respectively, and 1.4 percent spoke “Other Asian languages” (U.S. Census Bureau, 2013).

What the census data fails to show, however, is the linguistic and cultural diversity of the Asian population. Not only is the label "Asian" problematic and complicated, it also creates a picture of a homogenous Asian identity that erases the internal diversity that exists within different Asian populations. Using such a term ignores the fact that not all speakers of Asian origin identify as Asian (e.g. Lippi-Green, 2012, Park, 2008). Such mislabeling and false perception of a homogenous Asian identity can have great (undesirable) consequences and shape classroom practices and students' learning in a negative way. Thus, understanding the challenges that students might go through, such as adjustment issues and identity struggles, becomes important as they affect students' learning and development in various ways.

For example, Asher (2006), an international scholar, notes in her narrative about being a female minority academic that she has always spoken English (and other Indian languages, such as Hindi) at home. Nonetheless, when providing a former student with feedback on her assignment, she suggested that her student pay attention to grammar. This particular student 
responded by saying that despite the fact that Asher was not born and raised in the United States, her English was "good" as she was able to correct her grammar. In this reflection, Asher is positioned as an illegitimate speaker of English, simply because she is originally from India and speaks a different variety of English: how could someone from a different country correct a native speaker's grammar? It has been well documented in the American context that Asian teachers and teaching assistants are thought to be less effective, as well as having a foreign accent, even if they are native-born native speakers of English (e.g. Rubin, 1992). From Asher's anecdote, it is clear that language issues are socially situated and tied to questions of identity and power in societies (Woolard, 1998).

Although Asher's (2006) experience is only one example, it illustrates the complicated relationship between language, identity, race, and culture. Her experience also sheds light on other language-related issues, such as prejudice regarding the status of different varieties of English in the world. What emerges is a struggle for power and subordination that many linguistic minorities face in the United States through the process of "othering"-a process that often creates new and imposed identities on minorities - that manifests itself in everyday discourse (Lee, 2015). Moreover, Asher explains that in India, she did not identify as a South Asian woman or person of color as those were not identities that she needed in India. However, when she came to the United States, she realized that identities based on her physical appearance were imposed on her and that the negotiation of her new identities were context-specific.

While my experience in the United States has been somewhat different from Asher's experience, I have had concerns about my identity as a non-native English speaker in the United States. My parents, who are Chinese but were born and raised in Malaysia, moved to Sweden after they were married, which is where I was born and raised in an immigrant community. I 
grew up speaking Hokkien Chinese as a child, but I also learned Swedish, and I studied English in school, as well as other languages. As I speak several languages and because I am unable to point to one specific location and refer to it as my home-I have several homes-my linguistic and ethnic identity has been a mystery to many people. As an international Teaching Assistant

(TA) who came to the United States from Sweden to pursue a master's degree in TESOL, I have been reluctant to share my linguistic background with my students: would they think that I have an "Asian" accent? I was worried that biases against an "Asian" accent and stereotypes would diminish my role as an instructor.

As indicated previously, the educational demographics is changing, making it important to better understand the experiences and struggles that ethnolinguistically diverse students bring into the classroom and not let classroom practices be shaped by misconceptions and stereotypes about them.

\section{Statement of the problem}

Despite making up a large part of the American population, the research on identity construction, identity negotiation, as well as linguistic practices of speakers of Asian origin are understudied compared to that of other groups, such as African Americans, Latinos, and Native Americans. As Lo and Reyes (2009) explain, one issue has been that the notion of "Asian" as a singular identity still often prevails, yet, the very term itself erases the linguistic and cultural diversity of these speakers and simplifies their lived experiences. Another layer of complexity stems from the different generational experiences: some are first generation immigrants, some belong to the 1.5 generation group, while others are second generation immigrants. ${ }^{2}$ From these

\footnotetext{
${ }^{2}$ These terms are defined later in this chapter.
} 
generational differences, two stereotypical images of "Asians" are formed: first generation immigrants of Asian origin are often situated as non-English-speaking foreigners, which erases their membership in American society. On the other hand, second- and later-generation speakers are commonly seen as linguistically and culturally assimilated, making them invisible as they do not stand out.

Previous research on multilingual identities in the United States has emphasized language acquisition, heritage language maintenance, but in recent years, an interest in learners' identity negotiation and construction has grown and received more attention in applied linguistics, TESOL, and in other related fields, such as composition and linguistic anthropology (e.g. Bucholtz, 2009; Kanno, 2003; Lo \& Reyes, 2009; Reyes, 2007). Studies on multilingual identities and linguistic practices of individuals of Asian origin have addressed the relationship between language, identity, and stereotypes of Southeast Asian youths (Reyes, 2007), longitudinal studies on bilingual learners from adolescence to young adulthood (Kanno, 2003), and issues in identity, culture, and race in various educational settings, including student and teacher identities (e.g. Amin, 1997; Bucholtz, 2009; Park, 2012; Motha, Jain, \& Teccle, 2012; Quach, Jo, \& Urrieta, 2009; Seloni, 2012), and racializing teacher identities (e.g. Motha, 2006). Research on identity negotiation in applied linguistics has examined how bilingual and bicultural Asian immigrants and Asian Americans, including students and non-native Englishspeaking teachers (NNESTs), negotiate and construct their identities in various ways. These studies have highlighted the journey and experiences of Japanese returnees (Kanno, 2003), the linguistic negotiation of Laotian immigrant students (Bucholtz, 2009), East Asian NNESTs (Park, 2009, 2012), negotiation of teachers' translinguistic identities (Motha, Jain, \& Teccle, 2012), and the influence of race in East and Southeast Asian students' identity development in 
educational settings (Quach et al., 2008). Studies on South Asian Americans' linguistic identity is commonly focused on the relationship between identity, family, and religion (e.g. Inman, 2006; Kurien, 2005), the perception of South Asian American identities and racial selfidentification (Kurien, 2005; Morning, 2001; Park, 2008), with less focus on linguistic practices and strategies that they use to negotiate their identities. The type of data utilized in the previously mentioned studies was collected using different qualitative and quantitative methods, e.g. interviews, ethnographic observations, and surveys, while the use of published life writing and written narratives have not been explored to the same extent by researchers in TESOL and applied linguistics, although they have become more frequently used in recent years (e.g. Bell, 2002; Pavlenko, 2002).

My goal, with this thesis, is to expand on current research on multilingual identities by examining how multilinguals construct and negotiate their identities. As identity negotiations of South Asian American writers have not been particularly scrutinized through narrative inquiry, my aim is to expand on previous research and contribute to the discussion on identity by using published life writing, specifically focusing on South Asian American writers by carefully unpacking data from written narratives. By exploring how they make sense of their lived experiences through published life writing, the writers are able to share how they understand their identity struggles and their attempts at solving them: life writing gives researchers access to the emotional aspect that might not be possible to capture using other research methods. Further, what is interesting is not only the contents of the narratives, but also the discourse itself and how the writers position themselves in the text. Thus, the discourse can also reveal more about the experiences that the writers went through that might not have been obvious at first glance. As much of our identities are constructed — and contested —in the classroom, at home, and in 
everyday interactions, exploring how multilinguals address identity struggles in these particular domains in their narratives can highlight their identity struggles and how they attempted to resolve them.

With this study, I hope to demonstrate that written narratives, life writing specifically, can be useful in understanding multilingual student and teacher identities. By employing a narrative analysis, I will investigate the different spaces where the South Asian American writers' identities are contested, particularly in the educational setting and the familial space, which would allow for a more nuanced understanding of their identities and challenges that they went through. Lastly, I will investigate how they attempt to and manage to resolve these identity struggles, if they are resolved, that is.

\section{Research questions}

This thesis is concerned with the identity negotiation of South Asian Americans writers, using published life writing as the primary source of data, specifically memoirs and short narratives from narrative collections. The collection of life writing consists of narratives written by first generation immigrants, the 1.5 generation, and second generation immigrants. These generational comparisons can uncover identity issues that multilinguals might encounter during various stages of their schooling, whether it is during K-12 or higher education. With the goal of understanding their identity construction and negotiation in various spaces, the research questions emerge as follows:

1. What identity struggles do South Asian American writers experience in various spaces and how are these struggles resolved and addressed in their written narratives? 
2. What kind of themes and commonalities emerge in the South Asian American writers' narratives regarding their identity negotiation?

3. How do South Asian American writers identify with or label "Asian" as they refer to their ethnic identities?

By asking these questions, the goal is to contribute to the current discussion on multilingual identity construction by exploring the experiences of South Asian Americans through life writing. The struggles and challenges that these writers' experience can provide educators in K12 and higher education with a glimpse of the adjustment issues that students might go through, whether these students are first generation immigrants, 1.5 generation, second generation immigrants. Employing an informed and critical approach to pedagogy could improve the learning environment for linguistically and culturally diverse students.

\section{Methodology: Narrative inquiry, data selection, and analysis}

In order to address the research questions and give multilingual individuals the agency to share and make sense of their lived experiences, a narrative analysis approach was adopted. Narratives have, until recently, been neglected as a legitimate source of data as they are generally perceived as less reliable - for example, more "anecdotal" - and therefore incomplete and erroneous (Pavlenko \& Lantolf, 2000, pp. 156). Since data that is used in existing identity research generally comes from interviews, surveys, or ethnographic observations, the aim of this thesis is also to contribute to the discussion on identity research by using published life writing to extend the range of data that is used for research on multilingual identities. 
By conducting a narrative analysis, critical moments when the writers' identities were contested can be highlighted, as this would allow us to examine what choices these writers made in order to solve their identity struggles, but also understand what options were (un)available to them. Further, conducting a narrative analysis allows for an examination of these writers' attempts at resolving their identity struggles and how these writers' make sense of their own lived experiences as multilingual and multicultural individuals.

It should be noted that the purpose here is not to generalize, or provide a complete understanding of the experiences of, say, all South Asian Americans, as the purpose of narrative inquiry is not to make generalizations. The use of narratives in various ways, such as for case studies, provide researchers with an example of a range of individuals' thoughts and experiences, rather than a sample of the experiences of a particular population. Narrative analysis does not take away or diminish the authors' agency, rather, it gives them the agency that they need to make their voices heard: "the deeper struggle is to try to understand people on their own terms" and these accounts cannot, and do not, capture the complexity of a whole social group (Nieto, 2004, p. 7).

Therefore, narrative inquiry is the primary methodology of this study as it offers an indepth understanding of how South Asian American writers make sense of their experiences as multilingual and multicultural individuals. Life writing, as a genre, can provide multilinguals with a space to revisit their lived experiences, especially their identity struggles, and make sense of them. Moreover, Bell (2002) states that "stories are constantly being restructured in the light of new events" and "[they] do not exist in a vacuum but are shaped by lifelong personal and community narratives" (p. 208). She also points out that narrative inquiry allows researchers to understand experience, which is often disregarded in favor of outcomes, and that narratives 
highlights the temporal element of experience: our understanding of people and events change over time. As the researcher, my task is to make sense of how these writers make sense of their own lived experiences by allowing them to tell me their stories under their terms and conditions.

When analyzing these narratives, I looked at moments where the connections and interactions between their educational experiences, familial life, language, identity, culture, race, and ethnicity, all as mediated through language use. I conducted a close reading of specific moments and events in which their identities were contested, and attempted to understand how and why these incidents occurred, and how they were possibly resolved. By analyzing the discourse and rhetorical devices used in the narratives, I examined how the writers positioned themselves and how their identities were situated in the texts. As this study is informed by a post-structuralist notion of identity, I was also interested in how their identities shifted over time and what prompted these changes. The writers' experiences were compared across generations to bring to light any differences or similarities for a greater understanding of identity negotiation.

Again, the purpose is not to explain or re-narrate the experiences of South Asian Americans: these narratives can provide us with a glimpse of what others might struggle with and challenge misconceptions and assumptions that are attached to the labels, whether these labels are "Indian," "Asian" or "South Asian American." In other words, the authors' narratives can provide us with knowledge that can debunk existing stereotypes rather than perpetuating them. Thus, the goal with this method is to allow these complexities connected to identity and language to emerge and be explored.

As for the data that was used for this study, a corpus that consists of published life writing written by South Asian Americans was created using memoirs and short narratives. When selecting this body of work, the following selection-criteria was used: first, the writers had 
to discuss their educational experiences in their narratives, in addition to their home and family life because of the strong connection to education and identity formation. While the majority of the writers had gone through schooling in the United States, K-12 and/or higher education, Alexander, the first generation writer, did not go through schooling in the United States. She had already completed her education elsewhere and before migrating to the United States.

Second, the authors also had to address issues that intersected with language, identity, culture, race, and ethnicity, and particularly how these intersections shaped their identity construction and negotiation. It should be noted that the writers did not necessarily have to address language issues explicitly as I also looked at how they position themselves through their discursive practices and rhetorical devices in the narratives.

Moreover, I chose to include longer works, such as memoirs, and shorter but more targeted narratives that exclusively addressed identity issues and being multilingual and multicultural. These shorter narratives came from collections of narratives written by scholars and other professionals who addressed issues pertaining to language, identity, culture, and race. For each generation, I chose to include a memoir, supplemented with a shorter narrative for a more nuanced picture of the experiences of South Asian Americans. With this in mind, the selection of narratives ${ }^{3}$ are as follows:

\footnotetext{
${ }^{3}$ A more detailed description of the memoirs and narratives can be found in Chapter III.
} 
Table 1

\section{Overview of selected memoirs and short narratives}

\begin{tabular}{ll}
\hline Author and generation & Title, year published, and brief summary \\
\hline $\begin{array}{l}\text { Meena Alexander } \\
\text { First generation }\end{array}$ & Alexander, M. (2003). Fault lines: A memoir. New York, NY: The Feminist Press. \\
& $\begin{array}{l}\text { Alexander was born in India and raised in both India and Sudan. In the 1980s, she } \\
\text { migrated to the United States and is currently a professor at the City University of } \\
\text { New York. She addresses her struggle to reconcile her contradictory identities: she } \\
\text { feels that it is fragmented as she has lived in many different countries. }\end{array}$
\end{tabular}

Nina Asher

First generation

Monica Jahan Bose 1.5 generation

Padma Lakshmi 1.5 generation

Carmit Delman Second generation

Kavitha Mediratta Second generation
Asher, N. (2006). Brown in black and white: On being a South Asian woman academic. In G. Li \& G. H. Beckett (Eds.), "Strangers" of the academy: Asian women scholars in higher education (pp. 163-177). Sterling, VA: Stylus Publishing.

Asher, a university professor, came to the United States as an international student. She writes about her experiences as an "other" and struggling for legitimacy as a female in academia.

Bose, M. J. (1999). Multiple identities. In P. G. Min \& R. Kim (Eds.), Struggle for ethnic identity: Narratives by Asian American professionals (pp. 120-129). Walnut Creek, CA: AltaMira Press.

Bose was born and raised in Bangladesh and moved to the United States when she was 10 years old. She is currently a lawyer in New York City. She writes about belonging to multiple cultural spaces, and issues regarding race and assimilation.

Lakshmi, P. (2016). Love, loss, and what we ate: A memoir. New York, NY: HarperCollins.

Lakshmi, a model and television host, was born in India. She migrated to the United States when she was 4 years old, but shuttled between India and the United States as a child. She addresses issues related to being an immigrant and feelings of "in-betweenness."

Delman, C. (2002). Burnt bread and chutney: Growing up between cultures -A memoir of an Indian Jewish Girl. New York, NY: One World/Ballantine Books.

Delman was born and raised in the United States, but also spent some time in Israel. She writes about the challenges of growing up as an Indian Jew and finding her own space.

Mediratta, K. (1999). How do you say your name? In P. G. Min \& R. Kim (Eds.), Struggle for ethnic identity: Narratives by Asian American professionals (pp. 77-86). Walnut Creek, CA: AltaMira Press.

Mediratta was born and raised in the United States (although she spent a couple of years in India as a baby). Her narrative focuses on her journey on coming to terms with her bicultural identity. 


\section{Overview of essential terms}

One of the aims of this thesis is to challenge the terms that are used to describe people who are commonly referred to as "Asian." A large number of people who are culturally and linguistically diverse are labeled as "Asian," and this use of the term draws attention to certain issues as it does not consider internal differences among the groups that are described as such. Another layer of complexity is rooted in the fact that there are many terms that can be used and they all have slightly different meanings. There is also some confusion regarding who could be labeled as "Asian": some groups are included while others are excluded, and as with many terms based on race and ethnicity, they are disputed and contested. Other terms that require clarification include race, ethnicity, and culture, which will be defined in this section. A brief explanation of the terms first generation immigrants, 1.5 generation, and second generation immigrants will be presented as well. While a whole book could be dedicated for a discussion on each of these terms, this section is only meant to clarify how I use them in this thesis.

\section{Contesting the "Asian" identity}

The term "Asian" is highly problematic as the everyday usage of the term overlooks the multifaceted aspects of identities. Other terms are also available and widely used in various settings: "Asian American," "East Asian," "South Asian," "Southeast Asian," "Asian Pacific American (APA)," and “Asian-Pacific Islander." For example, the Census Bureau's definition of "Asian" includes people who originate from countries from the Far East, Southeast Asia, and the Indian subcontinent. On the other hand, the United Nation Statistics Division (UNSD) (2016) divides Asia into five different regions: Central Asia (e.g. Kazakhstan, Turkmenistan), Eastern Asia (e.g. China, Mongolia), Southern Asia (e.g. Afghanistan, India), South-Eastern Asia (e.g. 
Cambodia, Singapore), and Western Asia (e.g. Armenia, Saudi Arabia). Evidently, there is no agreed upon definition of "Asian," instead, there are multiple uses of the term and issues regarding who the term includes and excludes. To complicate matters even more, the people who are commonly labeled as "Asian" might not identify as such due to various reasons, such as religion or physical features, thus, the use of the term "Asian" remains inconsistent (e.g. LippiGreen, 2012; Park, 2008).

In this thesis, the definition of "Asian" that is adopted is a modified version of the one that is used by the Census Bureau: "Asian" refers to individuals who originate from countries in the Far East, Southeast Asia, and South $\mathrm{Asia}^{4}$ and I use the term South Asian American to refer to the writers as a collective. These choices were made to remain somewhat consistent with how the terms are used in existing research on the Asian population in the United States. Though I recognize the absurdity of including and excluding certain populations, there is no other term available that can capture the complexities of immigrant identities and the linguistic and cultural variations that exist internally. It should be noted that I do not necessarily support or endorse the use of these contested terms and their essentialist qualities, but for the time being, no other terms are available that can be used to facilitate this conversation about immigration identities.

\section{Race, ethnicity, and culture}

Other terms that needs clarification are race, ethnicity, and culture. When it comes to race, it is generally agreed upon that there is no biological race. Instead, there has been a shift from perceiving race as a "natural" classification of human beings to understanding it as socially constructed, meaning that the categorization of humans emerges from everyday speech and

\footnotetext{
${ }^{4}$ Since some of the writers refer to themselves as South Asian, I chose this term rather than Indian subcontinent.
} 
discursive practices (Alim, 2016; Lee, 2015; Markus \& Moya, 2010). In other words, race is not a quality that one individual or group of individuals possess:

Contrary to what most people believe, race and ethnicity are not things that people have or are. Rather, they are actions that people $d o$. Race and ethnicity are social, historical, and philosophical processes that people have done for hundreds of years and are still doing. (Markus \& Moya, 2010, p. 4).

Race is, therefore, not a set of intrinsic qualities that a group of people "naturally" have. Instead, race is realized in everyday speech through discursive practices. Following this sentiment, Lee's (2015) case study illustrates how race and racialized identities emerge from the everyday discourse in cross-cultural comparisons that might appear to be innocuous, when in fact, they are essentializing. Culture, as it was used in everyday speech by the participants in the study, became proxy for race through comparisons and differentiating groups of people based on nationality and certain remarks, such as "cultural differences" and "different cultures" (p. 88). In a similar manner, Alim (2016) asserts that, "rather than [being] fixed and pre-determined, racial and ethnic identities are (re)created through continuous and repeated language use" (p. 5). As the notion of race as biological has shifted, I consider race as socially constructed through everyday discourse and not as qualities that are intrinsic to specific groups of people.

Similarly, ethnicity is not an inherent quality, rather, it is something that we do and it is realized through everyday discourse (Markus \& Moya, 2010). Ethnicity is commonly thought of as a group of people who share a common language, history, culture, and originate from the same geographic area. This explanation appears to be straight forward, but it does not consider the fact that people are not bound to a particular geographic area for the simple reason that people migrate, and this brings up questions regarding legitimacy and who can - and who 
cannot - claim an ethnic identity. As the writers of the narratives frequently refer to themselves using ethnic terms, such as Indian and Bangladeshi, I will use ethnicity in this manner too in order to remain consistent, but it would also give the writers agency to define their identities on their terms.

Since culture is closely connected to identity, a brief discussion on culture is needed. As Kumaravadivelu (2008) points out, culture is one of the most difficult words to define. There is currently no consensus among scholars and it is defined in many ways. According to Moran (2001), culture encompasses five interrelated dimensions: products, practices, communities, perspectives, and persons (p. 24). On the other hand, the Center for Advanced Research on Language Acquisition (CARLA) (2014) defines culture as "the shared patterns of behaviors and interactions, cognitive constructs, and affective understanding that are learned through a process of socialization. These shared patterns identify the members of a culture group while also distinguishing those of another group." Highlighting the social aspect of culture, Kottak (2009) sees culture as learned behavior that is passed to generation after generation. It is shared by groups of people and it is symbolic, including verbal and non-verbal symbols.

With the absence of an agreed upon definition of culture, the definition that I adopt is a combination of the previously mentioned definitions of culture: it includes various objects, food, behavior, beliefs and ideologies, and these aspects are passed on to other generations and are shared between groups of people. It is important to emphasize the fact that culture is a living entity and changes over time and in various spaces, meaning that individuals can belong to different cultures throughout their lives. Moreover, what is interesting is not only what culture is, but what culture does and how it influences human behavior. It is particularly interesting when multiple cultures intersect and sometimes friction emerges from cultural conflicts among or 
between people. For example, when conflict develops from the interaction between the dominant culture and minority cultures, a power struggle emerges from this friction where identities are contested, often leading to the subordination of the minority culture and people who belong to it. In some other instances, friction can emerge within the same culture as well.

\section{Defining first generation immigrant, 1.5 generation, and second generation immigrant}

Lastly, clarifying how I use the terms first generation immigrant, 1.5 generation, and second generation immigrant is essential to understanding the lived experiences of the South Asian American writers. Each individual has a unique experience and it must be stressed that the time of arrival is also important in shaping one's identity. First generation immigrant is used to refer to those who arrived in the United States as adults. As for generation 1.5, I do not refer to international students who come to the United States to pursue degrees in higher education as many of these do not intend to remain in the country after they graduate. Instead, generation 1.5 refers to individuals who come to the United States before they were adults and enrolled in K-12, with no intention of returning to their home countries. Unlike international students, these students have not completed their education in their home countries, and although they might have developed their L1(s), they might not be literate in their first language(s). If they are literate, they have not had the opportunity to fully develop their literate abilities in their home countries before arriving in the United States. As for second generation immigrants, this category includes those who were born and raised in the United States or arrived as infants and have gone through K-12 and/or higher education in the United States (Ferris \& Hedgcock, 2014). 


\section{Organization of the thesis and chapter descriptions}

This thesis consists of five chapters. In this first chapter, the background and statement of the problem have been addressed to provide contextual information. An overview of the study, including research questions, methodology, and a description of essential terminology are also found in this chapter. Chapter II is divided into two parts and the first part introduces the theoretical framework that is adopted for this study, a post-structuralist perspective on identity. The second part of the chapter provides a literature review of previous research on multilingual identities. In Chapter III, I discuss my methodology—narrative inquiry — and I provide a rationale for using this method, and the selection of memoirs and narratives that were used for this study are introduced as well. I also discuss how I processed and analyzed the narratives, and other aspects of importance, such as researcher positionality and methodological limitations. The findings and data analysis are presented in Chapter IV, which divided into two parts and organized thematically. In the first part of the chapter, the findings of the content analysis of the narratives are presented, while the second part of the chapter is focused on the discourse and rhetorical devices. Lastly, Chapter V presents an analysis of my findings. In this chapter, I revisit the research questions and discuss my findings in relation to previous research, as well as future research on multilingual identities. The chapter is concluded with some final remarks about the possibilities of narrative inquiry and using life writing to understand multilingual identities. 


\section{CHAPTER II: THEORETICAL FRAMEWORK AND LITERATURE REVIEW}

\section{Part I: Theoretical framework}

\section{A post-structuralist perspective on identity}

The theoretical foundation of this thesis is grounded in a post-structuralist approach for investigating identity negotiation as this framework allows for a more nuanced understanding of identities (e.g. Norton Peirce, 1995; Pavlenko \& Blackledge, 2004). This perspective treats identities as fluid and contradictory, as well as changing over time and in various spaces, but its definition varies among scholars (e.g. Kanno, 2003; Norton, 2000; Park, 2012).

According to Norton (2000), identity is concerned with "how a person understands his or her relationship to the world" and "how that relationship is constructed across time and space" (p. 5). Norton's definition, then, includes the important element of time as part of the construction of one's identity, emphasizing that this development is a lifelong, never-ending process, which takes into account how a person's perception of who they are influences their identity. Her discussion on identity emphasizes how one perceives oneself and how this perception is shaped across time and space.

Wenger's (1998) treatment of identity is similar to that of Norton's approach, viewing it as "lived" and "a becoming," rather than a quality or trait, i.e. it is social and involves interaction with others and is not an innate quality or trait that someone possesses (p. 163). Elaborating on the connection between identity and practice, Wenger (1998) outlines five aspects of this relationship: identity is a "negotiated experience," "community membership," "learning trajectory," "nexus of multimembership," and "a relation between the local and the global" (p. 149). Wenger notes that we "not only produce our identities through the practices we engage in, but we also define ourselves through practices we do not engage in” (p. 164). From Wenger's 
standpoint, identity is very much a social activity that involves multiple participants and is always in flux.

Merging both Norton's (2000) and Wenger's (1998) viewpoints, Haneda’s (2005) description of identity encompasses multiple features: "(a) membership in a community in which people define who they are by the familiar and the unfamiliar, (b) a learning trajectory in which they define themselves by past experiences and envisioned futures, (c) a nexus of multimembership in which people reconcile their various forms of membership into one coherent sense of self, and (d) a relation between local and global ways of belonging to [Communities of Practices]" (p. 273). Haneda's combination of Norton's and Wenger's definitions of identitywhich could be seen as an attempt at capturing the multifaceted nature of identities-illuminates the difficulty in defining what identity is. Regardless, the considerations of identity that have been put forth emphasize the social aspect and intricate processes that are involved in constructing one's identity.

Emphasizing the social aspect of identity construction and the significance of sociocultural contexts, Clark (2013) states that "attention needs to be paid to the ways in which identities, and particularly social identities, are ascribed and constructed by others as well as by ourselves within specific social and cultural contexts" (p. 7). At the same time, Clark (2013) considers the role of one's innate qualities and sees identity as "being something constructed or emanating from within ourselves, or as fixed social categories" and "a sociocultural phenomenon that comes from and within local, interactional discourse contexts that are social and cultural in nature" (p. 7). While Clark considers identity to be co-constructed by both internal and external forces, she stresses the importance of not overlooking the sociocultural contexts that shape and 
construct our identities, echoing the social components of the definitions put forth by Haneda (2005), Norton (2000), and Wenger (1998).

We can say with certainty that there is no single definition of what identity is and how it is constructed, but it is clear that it does not take place in isolation as it is very much a social process. In many ways, constructing one's identity is about marking one's membership and belonging to specific social groups, but at the same time, marking one's distance, and even rejection, of other groups. Tajfel (1982), while acknowledging the limitation of the definition, sees social identity as "part of the individual's self-concept which derives from their knowledge of their membership of a social group (or groups) together with the value and emotional significance attached to that membership" and:

...however rich and complex may be the individuals' view of themselves in relation to the surrounding world, social and physical, some aspects of that view are contributed by the membership of certain social groups or categories. Some of these memberships are more salient than others; and some may vary in salience in time and as a function of a variety of social situations. (pp. 2-3).

In other words, when claiming an identity and membership with a social group, individuals signal which groups they are not part of or possibly even reject. Regarding the process of becoming, or sometimes even earning, a membership to a social group, Norton Peirce (1995) argues that it is through language that individuals are granted access to — or is denied access tosocial networks, and that learners are not passive in constructing their identities, i.e. they have agency and make their own choices. However, this does not mean that the claimed identities will be accepted by the members of the dominant group: claiming an identity can cause friction between a person and a group, as the group might not accept the individual for various reasons. 
Stressing the dynamic nature of identities and the importance of context, Norton (2010) argues that identities "must always be understood in relational terms: one is either a subject of a set of relationships (i.e. in a position of power) or subject to a set of relationships (i.e. in a position of reduced power)" (p. 350).

Although there is a lack of a clear-cut definition of what identity means and entails, it is apparent that identities are complicated and constitute an intricate process that extends over time and space and must be understood in relational terms. In this thesis, identity, or social identity, is viewed as constructed within the self and co-constructed in social interactions with other people through negotiation across time and space. Claiming an identity means that a person marks his or her membership with specific groups in society and simultaneously marks which groups they do not belong to. One's identity is always in negotiation with others and is a social activity that is based on past experiences that is in constant development over time and in various spaces. Moreover, Clark (2013) opts for the plural form, identities, rather than the singular form, identity, which will be adopted for this thesis as it aptly aligns with the post-structuralist notion on identities, i.e. that they are ever-changing and contradictory. The use of the singular form would not capture this view and the complex nature of identities.

That being said, due to the shifting nature of identities, identities can be contested and challenged: claiming an identity does not mean that membership is automatically awarded to the individual. While an individual has agency and the ability to make choices when constructing his or her identities, it might be limited in certain situations, as claimed identities can be contested by others. Not only are they multifaceted and ever-changing, the post-structuralist framework also differentiates between three types of identities: imposed identities, which are not negotiable in a particular time and space; assumed identities, which are accepted and not negotiated; and 
negotiable identities, which are contested by groups and individuals (Pavlenko \& Blackledge, 2004).

The distinction between these identity options is critical in understanding why some identities are contested and why others are not: within certain groups and contexts, specific identities might be imposed or non-negotiable at a particular point in time, which does not permit individuals to resist these identities. For example, even when individuals did not identify as Jews in Nazi Germany, they were not able to resist and negotiate this identity as it was imposed on them and they had little say in this matter.

In other cases, identities that are accepted and not negotiated, i.e. assumed, are commonly valued and legitimized by most individuals within the dominant space or discourse. These include such things as being monolingual or being a speaker of the dominant language in a particular country. Lastly, negotiable identities are the identity options that are can be resisted and contested by individuals and groups.

However, it must be noted once more that identity options that individuals have available are not fixed. Identity options vary across time and space, therefore, considering the sociocultural and historical contexts are important when analyzing which identity options are imposed, assumed, or negotiable. What is visible in this distinction between different identity options is the degree of agency that one has in constructing one's identity. Some identity options are imposed and cannot be resisted, other identity options can be negotiated, and some are not contested at all, but the temporal aspect cannot be overlooked and must be taken into account.

The fluctuating nature of identities allows individuals to claim multiple identities at different times and in different situations (e.g. Park, 2012). Indeed, "certain events may send people back to a prior language and a prior identity" (Pavlenko \& Blackledge, 2004, p. 6). 
Previously claimed identities can be rejected and vice versa, and they can be re-claimed and rejected again later on. They may reject certain identities associated with their first language(s) (L1), second language(s) (L2), and subsequent languages at one point, but embrace those identities once again later on, prompted by different events. Evidently, the relationship between language learning and learner identities is not linear: it is unpredictable and unstable.

Consequently, contemporary identity research has shifted from the essentialist notions of identity as fixed and efforts have been made to illuminate its multifaceted, contradictory, and ever-changing nature (e.g. Kanno, 2003; Norton Peirce, 1995; Park, 2012). In the multilingual context, "identities are negotiated in and through linguistic practices" and languages are not only seen as markers of identity but also as "sites of resistance, empowerment, solidarity, or discrimination" (Pavlenko \& Blackledge, 2004, pp. 3-4). With that in mind, this thesis aims to explore how South Asian American writers negotiate their identities, what identity struggles they go through, and how they position themselves and others in their narratives. This can shed light on unequal power relationships in society and how these power struggles affect them. In addition, their identity struggles can highlight what identity options were (un)available and which identities were contested. Multilinguals may negotiate their identities by resisting or accepting specific languages, varieties, linguistic forms, and identities that are imposed on them in their struggle to find and claim their voice (e.g. Bucholtz, 2009; Norton Peirce, 1995). As languages are not neutral, and when used as identity markers in multilingual societies, the inequalities become visible as some identity options are more valued than others. 


\section{Part II: Literature review}

\section{The intersections of language, identity, race, and culture}

There is no escaping the fact that education, and particularly language education, is political and is a domain in society where power struggles and uneven power relations emerge from the friction between different cultures. Urged by TESOL scholars, such as Kubota and Lin (2006), issues on identity, race, and culture cannot be avoided as English is taught worldwide in various settings and countries. The status of English varies greatly in different countries, not to mention the unequal statuses that different varieties of English have. Investigating the postcolonial status of English, Canagarajah (1999) suggests that scholars and educators go beyond the stereotypical dichotomies, e.g. being for or against the vernacular, and investigate what strategies individuals use to negotiate their linguistic identities in the community and classroom. Students with various experiences with the English language enter classrooms all over the United States each academic year, and each student brings diverse linguistic and cultural resources into the classroom. With such a diverse student population, it is imperative for educators to become aware of issues that intersect with identity, race, and culture as well as ideologies that inform classroom practices, particularly ideologies that uphold and disseminate essentialist beliefs.

During the last three decades, there has been a move towards a more inclusive approach and critically informed pedagogy. This approach draws on post-structural and postcolonial perspectives that seeks to problematize and question our practices and what we know (Pennycook, 2001). With this shift in perspective, language education is not seen as free from power and politics, thus, race is a subject that cannot be disregarded. As stated in the introduction, the student population in schools throughout the United States is becoming more diverse: minorities are projected to make up the majority of the student population and is 
estimated to increase in the coming years. The Asian population has grown significantly since the last census, making it more urgent to research power, identity, race, and culture in applied linguistics and TESOL, and in other fields that intersect with language and education. Following Canagarajah's (1999) footsteps, the stereotypical positions, e.g. for or against English, are not of interest or the focus of this thesis. Instead, the strategies that the South Asian American writers employed, the identity options that were (un)available, and what choices they made to construct their identities are of interest. In the subsequent sections, I will address issues that directly pertain to the Asian population in the United States that concern identity and assimilation.

\section{Struggling for legitimacy}

Evident from the previous discussion, the post-colonial status of English is much about power and status. Models for many TESOL programs are based on the prestige of - to use Kachru's phrases-Inner Circle ${ }^{5}$ varieties of English (e.g. the United States, Australia), which delegitimizes varieties that are spoken in Outer Circle (e.g. India, Nigeria) and Expanding Circle countries (e.g. France, China) (e.g. Canagarajah, 1999; Matsuda, 2003; Park, 2008; Seloni, 2012). More specifically, there is a prevailing Standard English ideology that that influences language education and other institutions and domains in society: “...language, the most fundamental of human socialization tools, becomes a commodity. This is the core of an ideology of standardization which empowers certain individuals and institutions to make these decisions and impose them on others" (Lippi-Green, 2012, p. 61). To illuminate this power hierarchy,

\footnotetext{
${ }^{5}$ I recognize that the boundaries between Inner, Outer, and Expanding Circle countries are not fixed, but for the sake of the conversation, these will be used to refer to the varieties of English that are seen as unmarked, e.g. North American English, as opposed to those that are marked, e.g. Indian English.
} 
Canagarajah (1999) uses the terms center and periphery ${ }^{6}$ to describe the relationship between different English speaking communities, i.e. native and non-native communities. Center is used to describe technologically advanced countries in the West, and in contrast, periphery refers to communities in former colonies, such as India. With the increased immigration from Asian countries, the linguistic identities that these immigrants bring with them, whether as students or teachers, might not always be legitimized or valued because of the prevailing notions of the ideal native speaker and the romanticized English varieties that are spoken in Inner Circle countries.

Exploring the identity construction and negotiation of Asian non-native English speaking teachers (NNESTs) through written narratives and interviews, Park (2012) argues that their multiple identities have been overlooked. By investigating the experience of NNESTs in TESOL programs in the United States, the construction of their linguistic identities can be brought to light, and issues they face in legitimizing their position as NNESTs. A participant from the study, Xia, felt like she had to prove herself to not only native speakers of English, but also other nonnative speakers of English in the communities that she existed in. As a result of her encounter with a Chinese American recruiter, Xia commented on the fact that it would be difficult to legitimize her bilingual identity in various English-speaking communities. Further, Xia had to negotiate her linguistic identities and struggled with reconciling them: she could not speak Chinglish in the classroom as that was not the place for such a variety.

Regarding her teacher identity, Motha discusses how her translinguistic identity influences and informs her pedagogical practices (Motha, Jain, \& Tecle, 2012). In her narrative,

\footnotetext{
${ }^{6}$ These terms are not without issues, and as Canagarajah (1999) states, the terms are limited as he wanted to distinguish native communities from non-native communities. Although the terms native vs. non-native could be addressed in a whole different chapter, the scope of this thesis does not allow for such an exploration. Thus, native communities would refer to those that use the unmarked varieties of English.
} 
she recalls an incident when a student asked about the pronunciation of tomato and she explained to her student that the pronunciation varies across English speaking communities:

I did not want students to think that I was teaching them a form of English associated with my Sri Lankan heritage if they believed that form of English would not serve them well. I hastened to explain, defensively; "I'm from Australia, so I say tom-ah-to."

Somewhere in my subconscious mind, aligning myself with Australia rather than Sri Lanka gave me legitimacy. Admitting to my next comment still makes me cringe: I then added; "The British say tom-ahto." To my mind, the British affiliation was the trump card of legitimate pronunciation. How would students have reacted if I had said, "In Sri Lanka, it's pronounced tom-ah-to?" (which is, indeed, exactly how it is pronounced in Sri Lanka.) (p. 17).

Distancing herself from Sri Lankan English, Motha did so to construct herself as a legitimate and competent teacher by aligning herself with Australian English, i.e. an Inner Circle variety, which was the more privileged variety in her mind. The conflict between various varieties within the classroom space is not unusual: Amin (1997), who is ethnically Pakistani, states that many of her students did not perceive her to be a native speaker as she was not Canadian, and consequently, not a native speaker of English. In other words, she was constructed as a non-Canadian and a non-native speaker of English, as the typical Canadian and a native speaker was constructed as white.

Sharing the concerns of being a minority in academia, Seloni (2012) states that she is "also haunted by fears of failing and marginalization due to my nonstandard accent, nonidiomatic language, and non-American background" (p. 147). In her reflective narrative regarding her teaching and position as a non-native English speaking educator, she writes that: 
I often catch myself attempting to fit into white-dominant values in classroom contexts out of fear of marginalization and, perhaps, a subconscious desire to fit into the mainstream. While my apparent whiteness may make my minority identity invisible at first, my lived experiences as a junior faculty member remind me frequently that I am also surrounded by the disempowering discourses of colonialism and linguistics homogeneity that consider differences a deficit. (Seloni, 2012, pp. 146-147).

Similar to Motha's experiences, Seloni also experienced power struggles in academia as a minority, reinforced by her ambiguous background as she has a light skin color and at the same time, she has an accented English, which makes her both invisible and an outsider. Not unlike Motha's and Selon's experiences, I have been reluctant to share my linguistic background with my students for the same reasons: I do not want to be seen an illegitimate speaker of English. I do not want my linguistic identity and competence to be questioned in the classroom, which is why I have made the effort of not revealing where I grew up and left my linguistic identity somewhat ambiguous.

As we can see, these experiences unmistakably illustrate the destructive outcomes of language ideologies that elevate the native speaker from Inner Circle countries, and how this marginalizes non-native speakers. The negotiation of their linguistic identities reveal the unequal distribution of power between various English speakers and the process of subordinating or "othering" of those who are not perceived as native speakers. From this tension, it is clear that the participants struggled with gaining a "full membership" to the communities or social groups that they existed in. Claiming an identity involves making linguistic and non-linguistic choicessome would even say sacrifices - that would allow individuals to become members of a social group (e.g. Quach et al., 2008). Rather than viewing this from the traditional positions-for or 
against English — what is interesting is the choices that the speakers made in these situations to become members of various social groups.

Not only are teacher identities negotiated in the classroom, it is also a contested space where students struggle with being recognized as legitimate speakers, evident in Bucholtz's (2009) ethnographic study about identity negotiation of Laotian students. In an informal interview with one of the participants, her use of non-native use of English was a source of amusement to her friends as it was different, which resulted in her feeling alienated. Quach et al., (2008) state that immigrants and minorities are encouraged to speak (American) English, and at the same time, they are asked to abandon and reject their home language and cultures. The participants in their interview-based study, university students in North Carolina, purposely chose to befriend White students, rather than Black or Latino students. Some students even transformed their physical appearance to fit in with their group of (White) friends. Besides making non-linguistic choices, the participants expressed concerns about preserving their native tongues: some could maintain their native languages while others experienced language loss.

In the same way, Bucholtz's (2009) study shows that bilingual and bicultural speakers constantly negotiate their identities to gain membership to social groups. One of the Laotian students made an active choice of using African American Vernacular English (AAVE) because it allowed her to successfully interact with other urban-identified teenagers, regardless of race or ethnicity. The interaction with these teenagers gave her a sense of belonging and her choice of adopting AAVE allowed her to become a legitimate member of that particular group. 


\section{The "homogenous Asian identity"}

The idea of a fixed Asian identity is a common assumption made by both the general public and even professional teachers and applied linguists (Kumaravadivelu, 2008). This issue of labeling people of Asian origin in the United States can be traced back to the early census collection: "Chinese" was first added in 1860 in California and other race categories were added subsequently (U.S. Census Bureau, 2012). Yet, the categories do not reflect the cultural and linguistic variations among the Asian population. "Asians" and "Pacific Islanders" were grouped together in a homogenous category in the 1990 U.S. Census, but dissent from scholars and the general public resulted in a modification of this category to recognize the diversity among these individuals (Hill, 2009). This resulted in a change of the racial categories to include seven subcategories: Asian Indian, Chinese, Filipino, Japanese, Korean, Vietnamese, and Other Asian (The U.S. Census Bureau, 2000).

As Lo and Reyes (2009) state, they are well aware of the shortcomings in using the term Asian Pacific American (APA) and the "absurdity of grouping the huge diversity of individuals that are classified under the APA umbrella together," but state that "the fact remains that APAs are often seen as a single group according to widely circulating American ideologies of race" (p. 4). Further, the label is used as "a politically convenient cover term for people who are as linguistically, culturally, and religiously as diverse as Chinese, Indian, Japanese, Filipino, Vietnamese, etc.” (Kumaravadivelu, 2008, p. 2). Even by using national identity labels, e.g. Indian, the internal cultural and linguistic diversity is erased. For example, there is a difference between being a South Indian as opposed to being a North Indian. As one of the participants that Rayaprol (1997) interviewed stated: "“It is a North Indian temple and we are not used to it. We cannot merge with them, as their culture is very different"” (p. 75). Not only is the term "Asian" 
unclear and problematic, it is also one-dimensional and the internal diversity that exists within countries is not reflected through the use of such a label. In addition, the regional identities are ignored in the process: being a Northern Indian was not the same as being an Indian from the South in terms of religious practices, food culture, language, and so forth. This particular participant expressed a strong regional identity and its importance to her Indian identity, which simplistic terms such as "Asian" and even "Indian" eliminate.

Complicating matters even more, certain speakers may not identify as Asian, which is particularly interesting in the case of speakers of South Asian origin (Lippi-Green, 2012; Park, 2008). In a study by Lo (2016) that explored the linguistic racialization of Asian Americans in a suburb where, for a long time, most residents were white Americans. As the immigration patterns shifted, the demographic makeup in that particular suburb changed and the presence of Asian Americans is more prevalent today, causing some tension between the residents. Through interviews conducted with the residents - the white residents - very specific images of the "Asian" residents and how they were positioned emerged. To begin with, "Asians" was not used to describe individuals of Indian origin. Instead, "Indian" referred to anyone from India, Pakistan, Bangladesh, Sri Lanka, or Nepal, whereas “Asian” was reserved for those of Chinese, Japanese, Korean, Vietnamese, Thai, and Cambodian descent.

Echoing the concern for the label "Asian," the issue concerning who is "Asian" and who is not was addressed in Park (2008). Second generation Asian American students were interviewed regarding their ethnic identity and racial labels, and appeared to be conflicted about the label "Asian" and whether or not it included people of South Asian origin. The students in the study explained that when they heard the term Asian American, the Asian populations that came to mind first were those of East Asian origin, followed by Southeast Asians and lastly, 
South Asians. A student of Indian origin identified Chinese and Korean people as Asian, but said that that he would label himself as Asian American because of India being located in Asia. On the contrary, a Chinese American student clarified that she thought of South Asians as "Asian Indians" rather than Asian Americans, although she was fully aware of India being located in Asia. She was unable to provide additional explanations for the exclusion of South Asians, other than differences in physical characteristics and cultures. These students were unable to resolve the "Asian" identity, underscoring the problematic nature of the label.

\section{Contradictory images of Asian Americans: "The model minority" and "the perpetual foreigner"}

People of Asian origin have been described as "the model minority," depicted as the ideal immigrant group as they could assimilate better than other immigrant groups. On the other hand, a less idyllic image of Asian Americans exists: they are perceived as perpetual foreigners who are unable to get rid of their accents (e.g. Lo, 2016; Wu, 2002). These contradictory images of Asian Americans as assimilated and part of mainstream society but simultaneously depicted as permanently alien and "othered" expose misconceptions and stereotypes that exist in society regarding the Asian population. This affects not only newly arrived Asian immigrants: those who have been in the United States for generations - including those who were born and raised in the United States and are American citizens — share this struggle too. As Wu (2002) puts it: "More than anything else that unites us, everyone with an Asian face who lives in America is afflicted by the perpetual foreigner syndrome" (p. 79). In a similar fashion, Lo and Reyes (2009) maintain that Asians "tend to be pigeonholed as either 'forever foreigners' or 'honorary whites"' (p. 7). 
For example, an article published by the Pew Research Center in 2012 depicts Asian Americans who arrived a century ago as "low-skilled, low-wage laborers crowded into ethnic enclaves and targets of official discrimination" but "[t]oday they are the most likely of any major racial or ethnic group in America to live in mixed neighborhoods and to marry across racial lines." This image of Asian Americans is not unproblematic and rather troublesome as a large population is depicted in this manner, which ignores the socioeconomic discrepancies.

Though some Asian groups are even perceived in a more "positive" light (e.g. the myth of the model minority), others portray them as passive, obedient, and lacking critical thinking skills. In reality, such stereotyping disguises the disparities between various Asian groups, and ignores the fact that not every Asian fits into this stereotype (Bucholtz, 2009; Kumaravadivelu, 2008; $\mathrm{Wu}, 2002)$. In other words, people of Asian origin are either invisible or labeled as the "other," which makes it a challenge for them to find their place in society when their roles have already been assigned to them through stereotyping.

\section{"How do you say your name?": Naming rights}

The title of this section comes from the narrative written by Mediratta (1999), a second generation Indian who lives in New York City and she is a Chief Strategy Advisor who works to improve public schools. In her narrative, she discusses her struggle with coming to terms with her name - Coveta — an experience that she shares with many others who have "difficult" names (not necessarily "foreign" names), myself included. Since names and identities are inextricably linked and having one's name mispronounced repeatedly or reluctantly replaced with an "easier" name robs individuals of their agency and right to construct their identities. However, the name change is not only about others imposing a new name on certain individuals: sometimes it is the 
bearer of the name that initiates the change due to various reasons. In many ways, the names are sites of negotiation and open for identity construction where names are taken, imposed, rejected, or altered, and the bearer of the name has different degrees of agency in this matter depending on the situation. It is not uncommon for individuals with "foreign" or "non-American" names to anglicize their names to remove the "foreign" elements of their identities. In the same way, Taylor-Mendes (2003) writes that "I think that if I had to change my name, I do not know who I would be" as she has been called "Co-se-to," "Co-zetch," "Co-set-tee," and "Cosetka" while her name, Cosette, is pronounced "Coz-et" (pp. 98, 101). As an ESL instructor, Taylor-Mendes has students with different backgrounds and shares her anecdotes regarding the anglicized names that her students adopted or were assigned:

In the weeks ahead I eventually ask the renamed students why they chose the names they did. Snow and Echo told me that their names were their own names translated into English... [and] Rocky... had chosen his name based on a hero or someone he had seen in a movie or on television. Both Eric and Brad liked the way their names sounded when they found them on a list of names on the Internet and tried them out on their host families. (Taylor-Mendes, 2003, pp. 100-101).

The students in Taylor-Mendes' ESL class changed their names for various reasons and chose different methods to change their names: some translated their names and others selected names off a list they found. What is important to note is that names do not only refer to individuals, i.e. telling apart one individual from another, such as differentiating me, Su Yin, from my friend, Katy: names also have the ability to mark "foreignness," i.e. separating certain individuals from those who have "normal," or unmarked, names. As one of Taylor-Mendes' students told her, "My Korean name is Eun-ha, but my host mother calls me Julie" (p. 99). Although it is not 
revealed who gave Eun-ha her "English" name, it is possible that the name change was done to accommodate the host mother.

So far, the treatment of multilingual individuals' name change has concerned the resistance to change their names. Looking deeper into people's names and naming rights, we can see that the issue of changing names is connected to language ideologies and cultural assimilation (Bucholtz, 2016). However, there are cases where a name change is supported by the bearer of the name. Through questionnaires and interviews, it was revealed that some of the Chinese ESL learners in Edwards (2006) chose to adopt an anglicized name as a way to maintain distance between them and their instructors. Using their Chinese names would indicate that their relationship was more personal than it was, such as being friends as opposed to student and teacher. For a different student, the name change was a way to keep her male teacher at a "safe distance and the use of her personal name, in the classroom, would have been too intimate" ( $p$. 99). These students adopted new names and created new identities for themselves for the new context, i.e. the classroom, that they were in, rather than feeling like they rejected parts of their identities and adopted imposed identities.

This discussion about naming rights and name change illuminate issues that arise in the classroom and multilingual learners' agency in constructing their identity. Names are not only imposed or reluctantly adopted or always filled with resistance. In some cases, these changes are resistance free and in fact a way for multilinguals to create a new identity for themselves. 


\section{CHAPTER III: RESEARCH METHODOLOGY}

\section{Using narrative inquiry to investigate multilingual identities}

The aim of this thesis is to understand identity negotiation by multilinguals, in this particular case, South Asian Americans. To study these writers' identity negotiation, narrative inquiry was employed and a corpus of published life writing, i.e. memoirs and short narratives, was created. Narrative inquiry, simply put, is an examination of texts, such as life writing, in order to understand how people make sense of their lived experiences. This choice of research methodology give the writers the agency to use their own voices to make their stories heard, and allowed me to investigate how they express and make sense of their lived experiences in their own words.

In the past three decades, narratives have been used in multiple areas of linguistics and in related fields, such as sociology, linguistic anthropology, and language education (e.g. Bell, 2002; Pavlenko, 2002). In previous research on multilingual identities, much of the data that has been used was often gathered using a range of qualitative and quantitative methods, such as interviews, ethnographic observations, and surveys. It has been more common to use other qualitative methods to research multilingual identities, whereas using narrative inquiry and published life writing has not been employed to the same extent. The limited use of narrative inquiry can be attributed to the traditional view that objective knowledge is the only legitimate form of knowledge: narratives have been considered to be less factual, incomplete, and anecdotal from a positivist stance. In contrast, qualitative inquiry accepts that human experience, such as identity struggles, is complicated and unquantifiable in many ways. Since research on multilingual identity negotiation through published life writing has not been explored to the same extent, narrative inquiry was chosen for this thesis to complement the work that is currently 
being conducted. Further, narratives allow individuals to make sense of their lived experiences, and give individuals the agency they need to make their voices and their stories heard under their terms and conditions (e.g. Kanno, 2003; Nieto, 2004; Pavlenko \& Lantolf, 2000). In this vein, I will contribute to the already-existing literature on multilingual identity by using published life writing as my primary data-source. The purpose is to extend the types of methodologies that have been used in previous research to include narrative inquiry that specifically focuses on the contents, language choices and rhetorical devices that they writers use in their narratives.

What is important to keep in mind is that the published life writing that was selected for this corpus was published in the United States with an English speaking, or Western, audience in mind. As Bell (2002) states:

Although the notion of story is common to every society, the stories themselves differ widely—one of the defining features of a culture is the story structures through which it makes sense of the world. The shape of our stories, the range of roles available, the chains of causation, and the sense of what constitutes a climax or an ending are all shaped by the stories with which we were raised. (p. 207).

As Bell argues culture plays a big part in the way we tell our life stories: what is told, who is part of the story, and how it is told. When it comes to published life writing and autobiographical work, they are generally thought of as western constructions, which could affect what type of information is absent or found in the narratives.

It should be noted that, while the stories themselves are of interest to me, what is important to highlight is the fact that my task is not to re-tell these writers' stories. My task is to make sense of their stories since "narrative inquiry requires [us to go] beyond the use of narrative as rhetorical structure, that is, simply telling stories, to an analytic examination of the underlying 
insights and assumptions that the story illustrates" (Bell, 2002, p. 208). With that in mind, what is of interest is how the writers make sense of their lived experience as they revisit critical moments and events in their narratives, and not necessarily the stories themselves.

In addition, Kanno (2003) maintains that unlike other qualitative methods like ethnography and case studies, researchers who use narrative inquiry are more interested in how the narrative itself is used to understand human experience, rather than simply exploring how it is understood from the actor's perspective. Moreover, narratives are considered to be "indispensable not only for individual experiences, but also for our understanding of our own identities and those of others," but the use of labels and terms, e.g. "female" or "student" would not adequately answer the question "who am I?" (Kanno, 2003, p. 9). Instead, the labels would merely describe what someone is, but to answer the who-question, we need to know their life story. The labels would only provide others with a superficial knowledge about someone, but they would not necessarily know them, and as Hardy (1968) puts it, "we come to know each other by telling, untelling, believing, and disbelieving stories about each others' pasts, futures, and identities" (p. 6). Then, in order to understand someone's identity, their identity struggles, and who they are - not what they are - it becomes necessary to explore and investigate their life stories, experiences, and meaning making through the use of narrative inquiry. That being said, it should be noted that there are those who do focus on the what-question, however, that is not the primary focus of this thesis.

For this study, published life writing was chosen in order to understand who the South Asian American writers are through their life stories as told by them. However, the narratives will not, and cannot, be used to generalize the writers' experiences or provide a complete understanding of all South Asian Americans. Instead, the narratives provide us with an example, 
rather than a sample, of a range of individuals' thoughts and experiences. As Nieto (2004) states, "the deeper struggle is to try to understand people on their own terms" (p.7). These accounts cannot, and do not, capture the complexity of a whole social group, and therefore, the narratives will not be used in such a way.

\section{Data selection: Memoirs and short narratives}

The published life writing that was selected for the corpus consists of memoirs and short narratives written by South Asian Americans. These narratives were published in the United States with an English speaking audience in mind and Table 2 provides information about the writers and the collection of memoirs and narratives. 
Table 2.

The selection of memoirs and narratives

\begin{tabular}{ll}
\hline $\begin{array}{l}\text { Author, generation, } \\
\text { occupation }\end{array}$ & $\begin{array}{l}\text { Origin, background, ethnic/racial } \\
\text { identification }\end{array}$ \\
\hline $\begin{array}{l}\text { Meena Alexander } \\
\text { First generation }\end{array}$ & $\begin{array}{l}\text { Alexander was born in 1951 in } \\
\text { Allahabad, India, but was partly raised } \\
\text { in Sudan where she learned Arabic in } \\
\text { addition to her first languages, }\end{array}$ \\
$\begin{array}{l}\text { Poet and professor at the } \\
\text { City University of New } \\
\text { York (CUNY). }\end{array}$ & $\begin{array}{l}\text { Malayalam and Hindi. She moved to the } \\
\text { United States in 1979. }\end{array}$ \\
& $\begin{array}{l}\text { Alexander received her degree in French } \\
\text { and English from Khartoum University, } \\
\text { and her Ph.D. in English from } \\
\text { Nottingham University. Before being } \\
\text { hired as a professor at CUNY, she spent } \\
\text { some time at several universities, such as } \\
\text { the University of Paris-Sorbonne. She } \\
\text { identifies as Indian. }\end{array}$
\end{tabular}

Nina Asher

First generation

Professor at the

Department of

Curriculum and

Instruction at the

University of Minnesota.

Monica Jahan Bose

1.5 generation

At the time she wrote her narrative, she was a lawyer in New York City.
Asher was born and raised in Bombay, India, where she completed her undergraduate and graduate studies. She began her graduate studies (second master's degree and $\mathrm{PhD}$ ) in 1988 at Teacher's College, Columbia and her current research focuses on post-colonial and feminist theory, globalization, multiculturalism, and Asian American studies. She identifies as Indian.

Bose was born in England in 1964, but grew up in Bangladesh (known as East Pakistan at the time until 1971 when Bangladesh became independent) before moving to Washington DC with her family at the age of 10 . Her mother is Muslim, and her father is Hindu. She identifies as Bangladeshi.
Title, year of publication, page numbers, and topics addressed
Asher, N. (2006). Brown in black and white: On being a South Asian woman academic. In G. Li \& G. H. Beckett (Eds.), "Strangers" of the academy: Asian women scholars in higher education (pp. 163-177). Sterling, VA: Stylus Publishing.

In her narrative, she addresses issues that concern "othering" and struggling for legitimacy as a speaker of a "nonstandard" variety of English, i.e. Indian English, and being a female minority scholar in academia.

Bose, M. J. (1999). Multiple identities. In P. G. Min \& R. Kim (Eds.), Struggle for ethnic identity: Narratives by Asian American professionals (pp. 120-129). Walnut Creek, CA: AltaMira Press.

She addresses topics related to her multicultural identity, especially how she navigates and blends her Bangladeshi heritage with American culture and practices. 


\begin{tabular}{|c|c|c|}
\hline $\begin{array}{l}\text { Author, generation, } \\
\text { occupation }\end{array}$ & $\begin{array}{l}\text { Origin, background, ethnic/racial } \\
\text { identification }\end{array}$ & $\begin{array}{l}\text { Title, year of publication, page } \\
\text { numbers, and topics addressed }\end{array}$ \\
\hline $\begin{array}{l}\text { Padma Lakshmi } \\
1.5 \text { generation } \\
\text { Model, television host, } \\
\text { and author. }\end{array}$ & $\begin{array}{l}\text { Lakshmi was born in } 1970 \text { in Madras, } \\
\text { India. When she was two years old, her } \\
\text { mother moved to New York City, and } \\
\text { she stayed behind in India and lived with } \\
\text { her grandparents before being reunited } \\
\text { with her mother at age four. She } \\
\text { maintained a close connection to India } \\
\text { as she shuttled between the United } \\
\text { States and India when growing up. She } \\
\text { identifies as Indian. }\end{array}$ & $\begin{array}{l}\text { Lakshmi, P. (2016). Love, loss, and what } \\
\text { we ate: A memoir. New York, NY: } \\
\text { HarperCollins. ( } 325 \text { pages). } \\
\text { In her memoir, Lakshmi addresses the } \\
\text { challenges she experiences as an } \\
\text { immigrant in the United States, } \\
\text { specifically addressing adjustment issues } \\
\text { and feeling disconnected from } \\
\text { mainstream society and torn between } \\
\text { American and Indian culture. }\end{array}$ \\
\hline $\begin{array}{l}\text { Carmit Delman } \\
\text { Second generation } \\
\text { Author, freelance writer } \\
\text { and educator. }\end{array}$ & $\begin{array}{l}\text { Born and raised in the United States, but } \\
\text { spent some time in Israel with her family } \\
\text { before returning to the United States. } \\
\text { Her mother is an Indian Jew, and her } \\
\text { father is a Jewish American of Eastern } \\
\text { European descent. Growing up, her } \\
\text { family struggled financially, which } \\
\text { sometimes made it hard for her to fit in } \\
\text { and be like her peers. She identifies as (a } \\
\text { Jewish) Indian. }\end{array}$ & $\begin{array}{l}\text { Delman, C. (2002). Burnt bread and } \\
\text { chutney: Growing up between cultures- } \\
\text { A memoir of an Indian Jewish Girl. New } \\
\text { York, NY: One World/Ballantine Books. } \\
\text { (261 pages). } \\
\text { Delman shares her story about growing } \\
\text { up as an Indian Jew in the United States, } \\
\text { and trying to find a balance between her } \\
\text { Jewish and Indian identities, and her } \\
\text { attempts at making room for American } \\
\text { culture in her life. }\end{array}$ \\
\hline $\begin{array}{l}\text { Kavitha Mediratta } \\
\text { Second generation } \\
\text { Executive director for } \\
\text { the Atlantic } \\
\text { Philanthropist. }\end{array}$ & $\begin{array}{l}\text { Born in } 1965, \text { New York, and raised in } \\
\text { the United States. However, she briefly } \\
\text { lived in India until she was three years } \\
\text { old before moving back to the United } \\
\text { States with her family. Her mother is a } \\
\text { Catholic from South India, while her } \\
\text { father is a Hindu from North India. She } \\
\text { identifies as Indian. }\end{array}$ & $\begin{array}{l}\text { Mediratta, K. (1999). How do you say } \\
\text { your name? In P. G. Min \& R. Kim } \\
\text { (Eds.), Struggle for ethnic identity: } \\
\text { Narratives by Asian American } \\
\text { professionals (pp. 77-86). Walnut Creek, } \\
\text { CA: AltaMira Press. } \\
\text { Mediratta discusses challenges in coming } \\
\text { to terms with her bicultural identity, } \\
\text { starting her narrative with a discussion } \\
\text { about her name, as well as issues } \\
\text { connected to assimilation and belonging. }\end{array}$ \\
\hline
\end{tabular}

Before I began my search for narratives to create my corpus, I developed a list of criteria

that each narrative had to fulfill in order to narrow down the focus of my project. When selecting

this body of work, the following criteria was used: first, I was mainly interested in specific

spaces where the writers' identities were contested, particularly the educational and familial

spaces. Naturally, the writers had to address their educational experiences, besides their home 
and family life because of the strong connection to education and identity formation. However, other domains, such as everyday life and daily interactions were not excluded. It should be noted that the majority of the writers have gone through schooling in the United States, K-12 and/or higher education, with the exception of Alexander, a first generation writer. She did not go through schooling in the United States since she had already completed her education elsewhere before migrating to the United States when she was appointed as a professor.

Second, the authors had to address issues that intersected with language, identity, culture, race, and ethnicity, as these intersections shape identity construction and negotiation. On the other hand, this meant that other aspects were excluded due to the limited scope of this project, even if they were addressed by the writers, such as gender or class, therefore, it was not possible to explore other aspects that shape identity construction.

Third, it was not possible to focus on the impact of class on the writers' identity negotiation. Further, the South Asian American writers examined in this thesis came from different socioeconomic backgrounds. For some of the writers, the financial situation shifted over time, i.e. some struggled financially and came from humble backgrounds. Regardless of their socioeconomic background, all of them have pursued higher education and have at least a bachelor's degree, some have obtained a master's degree, and others have doctorate degrees as well. In addition, the writers have pursued a variety of careers: some of the writers are still in academia, some are public figures, while others work for different organizations.

Fourth, while selecting the narratives, I did not purposefully exclude male writers as I did not seek to explore identity negotiation from a gender perspective. Originally, I had included a short narrative written by a male writer, but after completing the initial stage of data processing, I concluded that there was not enough information that could be used - the topics that I was 
interested in were not discussed in-depth—and as a result, the male writer's narrative was not selected. Additionally, most of the narratives that were available were written by female writers.

Lastly, I did not have a specific South Asian country in mind when collecting the narratives, as long as they met the previously mentioned criteria, although most narratives are written by female South Asian Americans of Indian ancestry. Whether their gender and ancestry shaped the contents of their narratives was not explored and outside the scope of this project.

Once I had developed these criteria, the next step was to gather narratives that fulfilled these requirements. The narratives that I have chosen are accessible at various institutions, such as universities and libraries, and they are available for purchase online. When searching for the narratives, I originally planned on using only memoirs and autobiographies. The availability of such works written by South Asian Americans was limited, and finding at least two narratives-

a memoir and a short narrative - for each generation was a challenge too. This led me to include shorter narratives written by scholars and other professionals that were part of narrative collections. Additionally, the narrative collections are more targeted at making visible the voices of minorities, specifically Asian minorities in academia and in other professions, unlike the memoirs that were selected that covered a range of topics. Once I had selected and obtained the narratives for my corpus, the next step was to conduct an in-depth reading of the narratives

\section{Data analysis: Unpacking the narratives}

After constructing my corpus of narratives, I developed a method for the data analysis stage, which included several phases. I created a system that allowed me to filter through the wealth of information that was available in the narratives, as I did not entirely know what was addressed in the narratives or to what extent the themes that I was interested in would be 
discussed. Naturally, then, the first step was to read through the narrative and mark sections that were relevant to my project.

During the first phase, I decided on a number of pre-determined terms that I would look for in the narratives. These pre-determined terms were: Asian (and other related terms, such as South Asian and American), language, identity, race, ethnicity, culture, education, family, and friends. Whenever I came across these terms as I was reading, I would tag that specific section as well as document it electronically by logging the page numbers and explain what was addressed in that section. This was particularly important for the memoirs as they were much longer than the shorter narratives in terms of organization.

After the initial sorting process was done, I began phase two, which entailed a more detailed processing of the marked sections. This meant that I reviewed each marked sectionwhich ranged from a couple of pages to a sentence — and selected those that seemed the most significant and critical to the writers' identity construction. At this stage, the most important part was to identify sections that addressed critical moments or events when their identities were contested. If an incident was critical or not was judged by whether or not the writers' identities were challenged, and particularly if the same incident occurred during several occasions. For example, as we will see, a recurring incident concerned the writers' skin color.

Once I had completed phase two, phase three involved a critical reading of the relevant sections that I had selected to illustrate the identity negotiation that the writers experienced. At this stage, I began comparing and contrasting the experiences of the writers in order to find common themes that emerged in their narratives. When analyzing the contents, I examined who was involved, and how the situation was - potentially-resolved. When I was in the processes of analyzing the selected sections of the narratives, I began to outline Chapter IV based on the 
emerging themes and commonalities that I found. I decided to divide the chapter into two sections, with the first section dealing with an analysis of the contents, while the second section of the chapter dealt with the narrative techniques and rhetorical devices that the writers use to construct their identities in the text itself. When analyzing the selected sections for this part of Chapter IV, I focused on how the writers labeled themselves and referred to others, how they positioned themselves, and how their multilingual and multicultural selves made their ways into the text. For example, I looked at the labels that they used, the linguistic choices that they made, such as if they used other languages than English, and if they did, how and when they did so. For that reason, what was important was not only what the writers had to say about their identities and their struggles, but also the choices they made to compose their narratives.

As noted earlier, the goal is not to re-tell the writers' stories and experiences. When analyzing the data, I focused on critical and pivotal moments in which their identities were contested. These moments were analyzed for underlying meanings and assumptions, and I attempted to understand why those moments were critical and important, as well as what identities were contested, and what the writers did to resolve their struggles. Further, not only did I focus on the actual events, i.e. the contents, I also focused on the text itself and how the writers positioned themselves and others in the texts and word choices. For example, it was evident that fragments of their multilingual identities made their way into their narratives through the use of non-English words.

\section{Researcher positionality}

I would like to introduce this section with a quote by Park (2012), regarding her own positionality in her research. Identifying as a non-native English speaking teacher, 1.5 
generation, and a Korean American woman, she states that her own identities and experiences are connected to the participants in her studies on a personal, academic, and professional level. The following quote comes from a study on how a NNEST comes to terms with her non-native speaker identity, in which Park (2012) writes that:

The very selection of this topic reflected a subjectivity and bias in that I could not divorce myself from the experiences of these women. Hence, this study, in and of itself, was a reflection of my personal and, to some degree, my academic experiences. (p. 131). Sharing that sentiment, I entered the field of applied linguistics and TESOL prompted by my own personal experiences — and my parents' experiences with identity negotiation in multiple communities - as a multilingual and multicultural individual, but also because of my curiosity and interest in the relationship between language and identity, love of languages, and teaching. I am a second generation immigrant, an international student, a non-native speaker of English, a heritage speaker of Hokkien Chinese, and a speaker of both "standard" and vernacular varieties of Swedish and English, especially the vernacular varieties of English! Each of these (marked) identities that I claim emerged from the conflict and tension between race, culture, and language that I have experienced, which have shaped who I am as a person and as an emerging scholar. Like Park, I cannot avoid seeing bits and pieces of my own life in the narratives written by the South Asian American writers. In a way, their stories are my stories.

Thus, this project emerged from my own personal investment in, and intellectual investment about issues of language and identity. When reading the narratives, I could relate to many of the writers' experiences related to identity struggles and being minorities. In fact, many of the issues they discussed — particularly having non-western names—are very much present in my personal, academic, and professional life. Just like the ESL students in Taylor-Mendes' 
(2003) classroom who replaced their names with western names, and Mediratta who modified the spelling of her name on several occasions over a long period of time, many people have struggled with my name as well. Throughout my life, both in the United States and Sweden, I have been asked why my name is not hyphenated to make it easier for people to pronounce it. My response is always the same: Chinese people do not hyphenate their names. Very often, people will respond with “it's just a hyphen," but is it really just a hyphen? No, it is not just a hyphen. The issue is not the function of the hyphen itself, rather, the issue is what the hyphen does to my name and how it alters is physical form: it removes and replaces parts of my identity because I am known as Su Yin, not Su-Yin. For most of my life, I would spell my name "Suyin" as I thought it would make life easier - it did not - and a few years ago, I decided to revert to the original spelling of my name because I could not fully identify with the anglicized way of writing it.

It is clear that I cannot approach this type of research addressing immigrant-related issues without somehow seeing my own stories reflected in the experiences of those that I study, which brings me to an aspect of qualitative research that is not discussed much in applied linguistics: reflexivity. Simply put, reflexivity concerns the processes of critical self-reflection on one's biases and acknowledges that the researcher is part of the setting and contexts that they wish to understand, and it can be used to critically examine the research process itself (Starfield, 2015). Regarding the use of the first person singular in academic writing, Starfield (2015) writes:

We have been instructed to remove all instances of first person. Please advise if these changes are acceptable. Thus read the copy editor's instructions in the track changes comment box alongside the opening paragraph of an entry I had written for an applied linguistics encyclopedia. (p. 249). 
The comment that Starfield (2015) received from the copy editor reflects a dilemma regarding the researcher's role, identity, and presence within a text: “...the first person singular pronoun is clearly, as Hyland (2012: 128) points out, 'the most visible manifestation of an authorial identity.' And its use or non-use is a source of confusion and anxiety to many student and scholarly writers" (p. 254). Should the researcher's presence be visible in the text or not? Should the researcher remain behind the scenes and removed from the subject matter? These are questions that often emerge in discussions regarding academic writing — and often brought up in my first year composition classroom - and these are questions that I, too, struggled with when constructing this thesis. Moreover, Ramanathan (2005) writes: "our growing understanding that there is no 'objective,' distanced observer, [and] that as 'researchers' we are an integral part of those we "study"' (p. 291). Elaborating on this statement, she explains that some of the complexities regarding the researcher's role and self-reflexivity concern the issues of speaking for others and how "languaging" or writing constructs selves and adds layers to already existing selves. As I was writing my thesis, it was especially difficult to find a balance between my different written voices. Should I be serious and formal in order to be perceived as a respectable scholar? Or maybe I should be less formal and incorporate some humor to connect with my audience? How much of my own experiences as a multilingual could I share in this thesis and still call it research? In other words, how much of my non-academic self could I allow to bleed into my writing, especially in such a formal document like a thesis? Knowing when and how to use each of these voices effectively without diminishing my role as the researcher was a dilemma that I faced throughout my writing process.

Although I cannot say that I managed to solve this dilemma, I did, however, find ways to blend my various written voices in this document without taking away from its main purpose. 
Traditionally, the researcher is supposed to be objective and not present in the text, but this particular view has shifted. Instead of constructing the researcher as removed from the subject matter, the researchers' role and objectivity have been questioned. Challenging the traditional beliefs of the researcher's role has allowed me to explore ways to incorporate my own nonscholarly identities into this document as I found that it was not possible for me to divorce myself from my own lived experiences from my scholarly identity. Further, it is not entirely possible for me to fully separate myself from those who I study. As such, I have not made an effort to hide or constrain my presence in the text, and instead, pieces of my own identity as a multilingual and multicultural individual have made their way into my writing. Therefore, when analyzing the narratives and when I engage in "languaging," my attempts at understanding how these writers make sense of their lived experiences also means that parts of myself are embedded in my analysis and writing.

\section{Methodological limitations}

Narrative inquiry was chosen for this project with the purpose of exploring how South Asian American writers made sense of their lived experienced as multilingual and multicultural individuals, while allowing them to make their voices heard and giving them the agency to do so through their narratives. As I was processing the corpus, I realized that there were some limitations to this particular methodology and source of data. First, one drawback was that I was only looking at their textual world instead of complementing the narrative analysis by interviewing these writers, thus, I was unable to ask them to clarify and elaborate on certain events that I found were crucial to their identity construction. Although I was unable to elicit more information and details, it does not mean that the narratives did not provide an insight to 
these writers' identity struggles and how they tried to make sense of their experiences as multilingual individuals.

Second, because the narratives were already written and printed, I had little control over the contents and I was unable to find exactly what I was looking for. While the writers addressed similar topics in their narratives, they did so to varying degrees. For example, one of the writers, Delman, discussed her skin color to a greater extent than the other writers. In contrast, she did not discuss her relationship with her name, unlike other writers, such as Mediratta and Lakshmi. In addition, the "Asian," South Asian, or Asian American identities — and how they identified with them-was not discussed in these memoirs or the narratives; much here concerned discussions of ethnicity, especially being Indian and Bangladeshi. In other words, when using only readily available data, such as published life writing, there is an element of uncertainty regarding the contents. Therefore, it was not entirely possible to build a more targeted corpus that specifically dealt with the topics that I wanted to explore in for this project, which to some extent also shaped by the scope of this project. However, the uncertainty was not all negative. The contents of the narratives surprised me and provided me with compelling data, such as the role of their skin color.

\section{Chapter summary}

In this chapter, I provided the rationale and justification behind my choice of research methodology — narrative inquiry — and explained how I selected and obtained the memoirs and short narratives that made up the corpus for this thesis. I also described the process behind the analysis of the narratives, as well as the limitations of this study. Finally, I also addressed my 
role as the researcher and my positionality, particularly the inability to divorce myself from my own experiences as a multilingual individual and scholar.

In the following chapter, my findings and interpretations of the memoirs and short narratives will be presented. The chapter is divided into two sections, where Part I contains the analysis of the contents of the narratives, while Part II is focused on the discourse and rhetorical devices that are used to construct the writers' identities within the narratives. The findings will be introduced thematically and each theme is centered around a selection of quotes that are related to the themes. 


\section{CHAPTER IV: FINDINGS AND INTERPRETATION}

\section{Overarching themes in the narratives}

From the analysis of the memoirs and short narratives, four overarching themes emerged and these themes were linked to the writers' adjustment and assimilation experiences: Theme 1 addresses how the writers were "othered," Theme 2 is focused on what labels they use to define and refer to themselves, Theme 3 addresses how the writers position themselves and others within their narratives, and lastly, Theme 4 is about the writers' linguistic identities and their relationship to different languages, particularly English.

First, Theme 1 concerns the ways in which the writers were "othered": many aspects of the writers' identities, mainly race, culture, national identity, and religion, often caused difficulties in daily interactions in various spaces. For example, two of the writers, Delman and Lakshmi, frequently discuss their skin color as a sign of "otherness" and as an indicator of their marginalized positions in society. Another recurring theme concerned the writers' names. The inseparable bond between names and identities highlights the writers' agency in constructing their identities, but what is interesting is that they did so in various ways. Moreover, one of the writers, Delman, focused more on her feelings of disconnection from the average American ${ }^{7}$ and her attempts at engaging in cultural practices that she perceived to be American. These three occurring subthemes_-skin color, names, and national identity — are connected through their common link to issues of belonging and being, or becoming, a legitimate member of mainstream American society.

\footnotetext{
${ }^{7}$ When I use the terms American or American identity, it is not my interpretation or definition of what is American - the views are based on how the writers define them. As we will see, the writers make link several aspects of American culture to the American identity, such as (junk) food and cultural practices.
} 
Second, the narratives themselves can be seen as a way for the writers to reconcile their identities by using linguistic and discursive means to (re)-construct their multilingual and multicultural identities within the text itself. In a way, this allows the writers to become whole, even if certain parts of their identities are contradictory and incompatible. Not only can the narratives be seen as a way for the writers to make sense of their identities, they also allow us to see how the writers view themselves in relation to others. Therefore, by examining how they use different labels (Theme 2) to define and position themselves and others in the texts (Theme 3), we can get a glimpse of how they structure and organize their worlds. Moreover, the linguistic identities and the linguistic choices that they made are worth mentioning as well (Theme 4). The memoirs and narratives were published in the United States with an English speaking audience in mind, therefore, it is no surprise that they were written in English. However, what is interesting is how the writers' multilingual and multicultural identities bleed into their writing. The use of English was not negotiable, but they did have agency and some flexibility regarding the linguistic choices that were made as they incorporated non-English words into their narratives. While it was not possible for them to write in another language but English as they were constrained by the social context that they were in, their agency was not entirely limited.

In the next two sections, I will present my findings and my interpretation of the memoirs and narratives. Theme 1 will be discussed in the first part of this chapter, and this section is concerned with the contents of the narratives. I will provide snapshots of critical moments where the writers' identities were challenged, interpret and discuss the choices that they made, and explore what identity options they made visible for the readers. The second part of this chapter is focused on the writers' linguistic choices and discursive practices, and how the writers position themselves in their narratives and how they construct their identities within the text. 
Moreover, not every writer addressed the same issues and when they did address the same topics and themes, the scope and depth varied. As such, the writers' stories will not be equally represented as I have only chosen to include the most critical moments, meaning that some writers' narratives are more frequently mentioned than others.

\section{Part I: Analysis of contents}

\section{Theme 1: Indexing the "other"}

\section{Physical attributes as markers of "otherness."}

Of the many signs that mark the "other," the writers' skin color is one of the most salient markers of their marginalization and a source of great conflict to the writers and others as well. This was most frequently addressed by Delman and Lakshmi. Incidents from their narrative reveal how their physical attributes, such as their non-white skin color, instills in them feelings of distance and alienation. On the other hand, Bose had a different experience regarding the color of her skin. Unlike Delman and Lakshmi, whose skin color garnered unwanted attention, Bose experienced the opposite; she became invisible. This section will highlight critical moments during which the writers' skin color marked their "otherness," how they attempted to resolve these struggles, and what the outcomes of these skin-related conflicts meant for their identity construction.

Issues related to skin color takes on a more central role in Delman's narrative. Growing up, her skin color evolved to become one of the most critical aspects of her being "othered" and source of disconnection from mainstream society:

But from the outside, no matter what the gradations in my mixed heritage, the shadow of Indian brown in my skin caused others to automatically perceive me as Hindu or Muslim. 
They could not imagine that I was Jewish because I did not look like a typical American Jew. And they attached to me a view of the world that spoke to my color only. Still I trekked through life with the spirit of a Jew, fleshed out by the unique challenges and wonders of a combined brown and white tradition. (Delman, 2002, p. xxiii).

Thus, Delman's identity, not only her brown skin, but as an Indian Jew was not the norm and she did not see herself mirrored in society. Despite the fact that she was born and raised in the United States, she notes that she did not fit into the white Jewish American stereotype as an Indian Jew. Because of her skin color, she was not fully accepted by the Jewish American community, nor was she viewed as a "real" Indian by the Indian community as she was not a Hindu or Muslim. To use her own words, her identity and authenticity as a Jew and an Indian was "mistrusted" (Delman, 2002, p. xxii). Within the Jewish community, “...people automatically identified us by the brownness and what made us nonwhite. Their assumptions drew a distinct line between us and them" and "[w]e, Ashkenazi Jews, are the pure originals. You, Indian Jews, are mixed products" (Delman, 2002, p. 151).

Therefore, Delman's skin color becomes a pivotal sign of her markedness in society and her status as an outsider, not fully accepted by the members of the communities that she wanted to be part of. This is especially noticeable when she discusses an incident after swim team practice at the Jewish community center. When getting dressed, she was surprised that the other girls had "lovely pink nipples":

I had never even thought about this, that nipples could come in any other color but brown-toasted, like my own... [the nipples] seemed to taunt me, superior. And I sighed, thinking enviously, this is how nipples were meant to be. I wanted pink nipples, too, I decided, not my plain old burlap ones. (Delman, 2002, p. 153). 
Most of the time, intimate areas of our bodies are covered up, exposing only legs, arms, and our faces, but this moment after swim practice, Delman realized that her body was entirely different. Not a little different, but every inch of her body was different, which further indexed her marginalized position in mainstream society. While there is no act of discrimination happening in this situation, her reflection exposes the internalized racism that, in a way, reflects how she viewed herself: as someone in a subordinate position who did not possess any of the characteristic traits of the dominant group.

For Delman, her skin color was a source of confusion, which prevented her from gaining access to the communities that she wanted to belong to. While she claimed membership to the Jewish and Indian communities, her membership was denied by the members as she did not "fulfill" the unstated requirements. The mistrust that stemmed from the established members' difficulty in reconciling Delman's non-stereotypical religious affiliation and her skin color made it hard for her to become a legitimate member of the Jewish and Indian communities. As both the Jewish community and Indian community did not see Delman and her family as legitimate members because of their skin color and mixed heritage, she explains that they had to prove themselves to others that they were "real" Jews and "real" Indians. What is visible in this tension is that the labels bring with them a set of assumptions and pre-determined identities, regardless if they are true or not. In this case, Jewish Americans are assumed to be white and Indians are assumed to be Hindu or Muslim, and these assumptions create a fixed set of identities that do not allow for internal diversity and variation. From the perspective of the community members, these identities appeared to be fixed and because Delman is of mixed heritage, her identity is an "anomaly" and a "deviation." In other words, these identities were disputed within the Jewish and the Indian communities. 
Similar to Delman's negative experiences, Lakshmi's relationship with her skin color was difficult and caused resentment as it was a part of her identity that she was unable to control. Additionally, in Lakshmi's narrative, the importance of skin color was reinforced through cultural and familial values. We can see that the prominent role that skin color has in her culture and family in the following quote where she describes the importance of not having dark skin:

As parents and grandparents often do in Asian countries, my extended family urged me to avoid the sun, not out of fear that heatstroke would sick me or that UV rays would lead to cancer, but more, I think out of fear that my skin would darken to the shade of an Untouchable, a person from the lowest caste in Indian society, someone who toils in the fields (Lakshmi, 2016, pp. 103-104).

Within the Indian community, a light skin color signals an unmarked status and Lakshmi was urged not to become darker. Whereas her skin color was a sign of her unmarked identity within the Indian community, to mainstream society in the United States, her "brownness" represented her marginalization as the "other" since the average American was constructed as white.

In Lakshmi's life, her skin color was a source of bitterness that was present in the educational setting and everyday life: "I hated the fact that my dark skin marked and mottled easily..." and further, she states that "... what I truly disliked, in certain gloomy moments and not always consciously, was my skin color itself, of which all that other piffle was merely a reminder" (Lakshmi, 2016, p. 103). The tension that emerged from this conflict began to influence her and she writes that "I began to change into a person who contained two people within herself: a girl proud of and connected to her culture and native country, and one who wished she just looked like her old doll, Helen" (Lakshmi, 2016, p. 105). When Lakshmi was still in school, she realized that her name was a part of her identity that she could change, unlike 
her skin color. Therefore, she chose to change her name to Angie, but notes that "of course my skin color and the other markers of my ethnicity — my dark eyes and fine, straight black hairwere immutable" (Lakshmi, 2016, p. 116). She could modify other aspects of her identity, but her skin color and other physical traits were markers that she was unable to change.

While Delman and Lakshmi received unwanted attention due to their physical featuresmostly because of their skin color-another writer, Bose had a different experience. During a student-run racism workshop that she attended in college, participants were asked to share any encounters with black/white racism. She did not identify as black or white, which she pointed out during the workshop, but was told that the workshop was about black/white racism, resulting in her feeling excluded:

I was the only person in the workshop who was neither black nor white. At the end of the workshop, I tried to talk about how I felt and mentioned how ironic it was that I was feeling this way during a workshop on racism. I did not sense a lot of support from the group. (Bose, 1999, p. 124).

The workshop reveals that racism was seen from a black and white binary, rather than a spectrum, and by seeing racism from one perspective, Bose became invisible.

As the writers' snapshots illustrate, the issue of skin color was a source of resentment, marginalization, and in other instances, invisibility. Despite their different experiences, their skin color remained one of the most obvious markers of their "otherness" in multiple spaces: local communities, at home, at school, and everyday life. The way the writers' perceived themselves and how people in their communities perceived them were at odds with each other, and in some cases, this made them invisible, (Bose), or visible but in a negative way, (Lakshmi and Delman). While they were unable to change their skin color, there were other parts of their identities that 
they could change, which we will see in the upcoming section concerning the relationship between names and identities.

\section{The relationship between names and identities.}

For Lakshmi, Alexander, and Mediratta, their names were a source of internal struggle and marked their "otherness" in distinct ways. Each writer developed a complicated relationship with their names, which prompted them to change or alter their names. The outcome of this problematic relationship with their names evolved differently for each of the writers: Lakshmi opted for an American name, Alexander decided to replace her anglicized names for an Indian name, whereas Mediratta modified her Indian name on several occasions for a long period of time before making a permanent change to her name. On the other hand, Bose had a different experience and did not change her name, as we will see in the following discussion.

When the new schoolyear started, Lakshmi was often able to detect when her teachers had reached her name on the roster as they were unable to pronounce name and would often stutter. This prompted her to change it to Angie — after the name of her mother's friend — from Padma. At the time she changed her name, she developed a greater awareness of the common practice of changing names: "Hae Sun became Susie. Marisol became Lisa. I'm pretty sure my friend Lynn was not a true Lynn" (Lakshmi, 2016, p. 116). She chose the name because she wanted to blend in and not attract attention to herself, but then she realized that she did want to be noticed, but in a positive way, so she changed it to Angelique later:

At the time I became Angelique, India - for most Americans I encountered-connoted smelly, poor, and weird. I felt both American and Indian. But I had to pick a side, and I decided I'd choose the least conspicuous one. I wanted to fade in, not stand out. A new 
school meant another round of hazing, but... it also presented an opportunity for reinvention. And while I couldn't change the way I looked, I could change my name. (Lakshmi, 2016, p. 115).

What we can see in this quote is that Lakshmi recognized that she had agency, and she made the active choice of changing a part of her identity that was possible to change, unlike her physical traits that marked her "otherness," such as her skin color. Changing her name could be seen as attempt at "unmarking" herself, thus, she chose Angie, a common American name. She did not use her given name for four years until she made a realization about her name changes: "I suppose I wanted to be noticed, just not for the reasons I was noticed as Padma" (Lakshmi, 2016, p. 116). By changing her name, she rejected parts of her Indian identity, in an effort to change the way that her peers viewed her, which was her way of resolving a conflict. Rejecting her name was a means for her to resist subordination and move closer to becoming part of mainstream society and accepted by her peers. As she learned years later, taking a non-Indian name did not change the way others perceived her, and by extension, the way that she was treated because she was unable to change her skin color, her eyes, and her hair as they were "immutable": "I began to see that changing my name was futile. A name is a marker of identity, but there are markers we cannot change, like the color of our bodies" (Lakshmi, 2016, pp. 116, 123).

Lakshmi's decision to change her name not only once, but twice, reveals her long struggle as a bicultural individual. As her identity as Padma was contested, opting for a more inconspicuous name, such as Angie and Angelique, was done with hopes of shifting her position from a marginalized position in society. Changing her name shows that she tried to solve her identity struggles, and from her perspective, a change of name was an attempt at ending the 
conflict. However, when realizing that changing her name was fruitless, she re-claimed her previous identity as Padma.

While Lakshmi decided to replace her Indian name with more common American names to make herself less visible and reduce her "otherness," Alexander chose a different route. Alexander was born as Mary Elizabeth and her names are anglicized versions of her two grandmothers' names. Although Alexander was known as Meena, she officially claimed this identity and name when she was fifteen:

I felt I had changed my name to what I already was, some truer self, stripped free of the colonial burden... It is also the home name my parents had chosen for me at birth. It is the name under which I wished to appear. (Alexander, 2003, p. 74).

In Alexander's case, her names connected her to India's colonial past and heritage, rather than her Indian roots and identity. Rejecting Mary Elizabeth was a way for her to separate herself from the colonial heritage and the western identity, and simultaneously reinforcing her own Indian identity by choosing Meena over Mary Elizabeth. In addition, it was under this name that Alexander had started to write poems, so she was known as Meena, the poet, and it was also used by her family already. In a way, there was already a distance and disconnection between her and her anglicized names. By choosing the name Meena, she chose her Indian identity, and as she states, to get rid of the "colonial burden" as the names Mary Elizabeth came with a set of identities that she could not identify with. In fact, those names came with identities that she rejected.

Struggling with coming to terms with her name, Mediratta states that her birth name, Coveta, which means poem, was meant to be graceful but "[w]hen my name rolls off the American tongue, it sounds heavy and ugly. Ca-vetta... Cav-i-tha ... Cuv-uda... I have a name 
that never fails to draw attention and that no one can pronounce" (Mediratta, 1999, pp. 77-78). In an effort to bring together her bicultural identities, her name underwent multiple modifications throughout her life, calling herself "Coveta, Cavetta, Cov, and now Kavitha” (Mediratta, 1999, p. 78). In retrospect, she writes that changing her name was her search for a sense of belonging and becoming part of mainstream American society.

Despite the struggle she experienced, she is now able to reconcile her Indian and American identities: she has formally changed the spelling of her name-Kavitha—and she is "less concerned about whether or not people pronounce it correctly" as opposed to when she was younger when she saw herself as a coach who helped people pronounce it correctly (Mediratta, 1999, p. 85). The reason, she states, is because the pronunciation of her name "has little bearing on my connection to India" (Mediratta, 1999, p. 85). Mediratta's perspective shows that her connection to India is internal, and does not take a physical form, such as her name. In other words, her connection to India is deeply rooted in her being and that the actions of other people could not sever her connection to India by mispronouncing her name. By recognizing that by changing her name she could change her perspective-and that she had the agency to change, or not change, her name - she realized that other people's actions did not determine who she was. Likewise, people's actions did not determine which identities she decided to claim for herself, even if others might reject or challenge them.

While Lakshmi, Alexander, and Mediratta changed their names, Bose, on the other hand, did not:

Although I have a Bengali name, it does not sound "ethnic" to most Americans. Recently, someone at work asked me how I got such an Anglo name... Monica is also a Bengali 
name and means "small gem.” My parents purposefully chose international-sounding Bengali first names for me and my sister, Anita. (Bose, 1999, p. 127).

Bose's anecdote shows that her name did not stand out in the United States and it did not become a source of conflict as it was to Lakshmi and Mediratta who changed their names. On the other hand, Bose's experience reveal another issue: her coworker asked why she did not have an "ethnic" name, and in a way, assumes that Bose is supposed to have one because of her heritage. She also notes that her parents purposefully chose international names, which in this case refers to names that fit into an American or western context. Additionally, her anecdote also reveals a conflict that parents face: while her parents wanted her name to have a connection to their Bengali heritage, opting for an international name would make it easier for others to pronounce her name and it would not be contested and challenged because of its "foreigness."

As the writers' anecdotes illustrate, the incentive and motivation for the name changes varied for each of the writers. While Lakshmi, Alexander, and Mediratta made different choices regarding their name change, the motivation behind the changes illustrates the choices that they made as multicultural individuals with non-mainstream American names. In contrast, Bose did not change her name as it was not a source of conflict or contested by others in a way that Lakshmi's name was. Instead, her parents made the choice of giving her a name that would reflect her Bengali heritage, as well as fit into a western context.

The writers' experiences suggest that one's identity construction and negotiation is unmistakably an ongoing process but also non-linear in nature. For example, this can be seen in the case where Lakshmi rejected her given name, adopted two different aliases during a four year period, before re-claiming her old identity as Padma. In a similar way, Mediratta's difficulty coming to terms with her name span across several years and her name underwent many changes 
before she finally settled with a version of it that she liked. Not only did she change her name, she also changed the way that she viewed the role of her name: regardless of how people pronounced it, her connection to India would still remain.

Moreover, the choices that the writers' made also highlight their agency. They were engaged in a constant negotiation process where they tried to construct their identity on their own terms, though each writer did so in different ways. In Lakshmi's case, she chose to re-

invented herself. Although her actions were prompted by external events - her identity as Padma was contested - she made the active choice of changing her name when she was not required to do so. On the other hand, Alexander rejected the symbolic meaning of her name and the connection to colonialism, which motivated her to replace her anglicized names as they did not reflect who she was. Not only do names act as identity markers, they also come with a set of predetermined identities, e.g. Alexander's names were associated with "whiteness" through their connection to colonialism, but she did not identify as such. In Bose's case, her parents' decision to give her a name that fit into a Bengali and western context shows that multicultural individuals modify their names to fit into the new context, illustrating that individuals in a subordinate position accommodate the needs of those in the dominant group. Overall, the relationship that the writers have with their names illustrate long journeys where they rejected, claimed, and reclaimed certain identities, before settling with names that they identified with.

\section{Being (un)American.}

To better understand the narratives, we must attend to how, during the writers' childhoods, much of American society had a superficial understanding and knowledge of Indian culture and often positioned it as an exoticized "other": India was associated with "third-world 
slums," "hot curry," and seen as "smelly, poor, and weird" (Lakshmi, 2016, pp. 105, 115). For the writers, particularly Delman, Bose, and Lakshmi, who grew up in homes where they were introduced to Indian culture and cuisine, certain cultural practices that they engaged in were not seen as American. As such, Delman, Bose, and Lakshmi expressed feeling like outsiders as they mostly grew up in Anglo American communities. Moreover, Delman, who is a second generation Indian, had very little connection with her mother's home country, and as an Indian Jew growing up in predominantly white community, she stood out. In contrast, Bose and Lakshmi moved to the United States as children. Bose, a native of Bangladesh but also spent some time in Pakistan, moved to the United States when she was ten years old. As for Lakshmi, moving to the United States as a four year old did not prevent her from maintaining a connection to India as she spent her early years there and she shuttled back and forth between both countries for a long time. In this section, the snapshots that I have chosen illustrate the identity struggles that Delman, Bose, and Lakshmi experienced that mainly concern feelings of in-betweenness, belonging, and their endeavors to find a place for their Indian and American identities to co-exist within themselves and in communities that they existed in.

Although Delman was born and raised in the United States and is an American citizen, she did not feel like she was part of mainstream society because of her unique heritage as an Indian Jew:

The truth is, officially I have always been an American. I'm a citizen. I was born here and raised here for the most of my life. And yet, growing up, I sensed that our home, and its exotic smells and languages, set us apart from something else. (Delman, 2002, p. 55). In the eyes of the law, she was American, but she did not feel like she was because of her conflicting identities. Regardless, there were moments in her life that made her feel like she 
belonged, and she specifically discusses the role of the station wagon. Riding in a station wagon made her feel American because of what it represented: the image of the average, white, Christian, American family. For a few moments, she was able to be part of the mainstream simply by riding in a station wagon. It represented something that was typically American-i.e. what she was not, but what she wanted to be —and although she technically was American, the station wagon fulfilled a real requirement for becoming an American.

Another symbol that represented "Americanness" that made Delman feel connected to it was the fast food culture. She recalls that whenever she and her family went on a trip, the dietary rules changed, and she states that it was "a treat to throw out words that seemed to permeate the lives of all other Americans," so, seemingly trivial acts like ordering a Happy Meal made her feel American because it represented the American identity and "Americanness," and consuming fast food allowed her to be part of it (Delman, 2002, p. 66). Further, she notes that "[t]his food was not kosher or spicy. But it came with bendy straws and toys and ketchup bags on the side. And that was enough" (Delman, 2002, p. 66).

Besides consuming foods that Delman perceived to be typical American, there was another activity that she wanted to participate in as well: going to the mall. As teenagers, going to mall with one's friends is common and possibly an activity that one is expected to participate in. However, in Delman's case, the notion of going to the mall was familiar, but how to fully participate in this specific activity was unfamiliar to her as her parents restricted the activities that she could participate in. At one point during her adolescent years, she asked her parents for permission to go to the mall because it was an activity that she wanted to engage in as it was something that her peers did. If she did it too, then she could fit in: 
At thirteen, I demanded that my parents give me at least the freedom of the mall, as it seemed everyone around me had this. They allowed it hesitantly, in random bits and pieces. And in the end I did not quite know what to do with it. When I went to the mall, I did not meet up with anyone there or get a job serving tacos. I did not buy makeup or play arcade games or see movies or try on clothes just for fun. Instead I walked around aimlessly, alone, watching other people walk around with their friends. (Delman, 2002, p. 120).

What is clear from this quote is that there is some disagreement between Delman and her parents regarding her going to the mall. Even though her parents reluctantly allowed her to go to the mall, her parents' view on what she should or should not be doing directly clashes with what typical American teenagers do-in this case, going to the mall—which was another marker of American identity and "normalcy." What we can see is that going to the mall encompasses more than being physically present at the mall. Going to the mall was not the activity itself, rather, it was the other activities, such as shopping or playing arcade games, that one did with friends. Since Delman went to the mall alone, without friends, she was unable to fully participate in this particular activity, thus, her attempt at becoming "a normal teenager" was not entirely successful.

In her efforts to resolve her identity struggles, Delman opted to participate in activities that she perceived to be American: consuming foods that were typically seen as American or going to the mall allowed her to be part of the norm. Her participation in these activities did not change the way people perceived her, but these activities enabled her to feel that she belonged. At the same time, the choices that she made also meant that some identities were sidelined and overshadowed. In other words, did she want to be an average American, Jew, Indian, or an Indian Jew? From her perspective, these identities were not possible to reconcile at the time 
because her identity as an Indian Jew was questioned by communities that she wished to be part of and in spaces that she existed in:

Most of all, I wanted to get far away from everything that was Indian or Jewish because these were the things that I felt branded me as the uncomfortable stranger. They made up the core of my vulnerability. I knew that the curry smell seeped from my very pores, alerting those around me like the musk of a fearful animal. (Delman, 2002, pp. 119-120). It is clear that her Indian and Jewish identities were seen as the source of her marginalization, and were iconic of her being "different," consequently, she actively sought to distance herself from those identities by engaging in activities that she thought would make her become, or be seen, as American.

As Bose came to the United States as a child, she had spent her first years in England before moving to West Pakistan as Bangladesh was not independent at that time. Regardless, she had developed her Bengali identity before moving to the United States. When it comes to issues of assimilation and being American, she recalls a conversation that she had with a friend: ...I was shocked when a high school friend, a Caucasian, told me he thought of me as 'white.' I was extremely offended and asked him how he could possibly think that. He explained it was because I did not speak with an accent and seemed totally assimilated. (Bose, 1999, p. 127).

Bose shares that being thought of as white was offensive to her, as she did not identify with the American identity. From her perspective, she was Bengali, not American. Bose's view of herself was incompatible with her friend's perception of her: despite spending most of her life in the West, she has a very strong connection with Bangladesh and the rest of South Asia as these connections have shaped many aspects of her identities. In contrast, from her friend's 
perspective, being "accent-free" meant that one had assimilated and become part of mainstream American society. It was the sign of those who were unmarked, as opposed to having a (foreign) accent, which indicated marginalization. In other words, by viewing her as "accent-free" and, thus, assimilated, the colorblind attitude erases Bose's experiences as a minority.

In contrast, in interactions with other South Asians, particularly Bengali men, Bose found that they thought of her as "aggressive" and "very Americanized" because her view on relationships and dating departed from the more traditional Bengali traditions (Bose, 1999, p. 126). As such, she is not seen entirely as a Bengali woman by Bengali men because of her Western values. Even though the Bengali community did not necessarily reject her as a legitimate member, she is not entirely recognized as a "true" Bengali. Although Bose has had a difficult time reconciling her Bengali and American identities, she writes that:

Living in the U.S., I developed a broader South Asian identity. In the last few years, especially after becoming a U.S. citizen, I have finally begun to also see myself as an American. Although earlier I had thought that I might not want to become a U.S. citizen, I later changed my mind. It became clear that I would spend most of my life in the U.S., and I felt it was time for me to become a citizen and to really become a part of this country. The fact that the U.S. and Bangladesh recognize dual citizenship also made the decision easier. (Bose, 1999, p. 127).

Living in the United States reinforced her South Asian identity as a minority, and even after obtaining her American citizenship, while retaining her Bengali citizenship, she did not claim the American identity right away. Despite the symbolic meaning of obtaining a citizenship, it still took her some time and effort in order to view herself as American. While becoming an American citizen was a choice that she made to become American, it was not enough for her to 
feel like she was American. What made her choice easier was the fact that she was able to retain her Bangladeshi citizenship, meaning that she did not have to officially reject that aspect of her identity. Instead, becoming an American citizen meant that she was able to reconcile both identities internally as her identities were legally accepted and recognized as well.

Like Bose, Lakshmi moved to the United States as a child as well. She writes that she did not realize until later that moving to the United States was "more than a crossing of oceans and continents; it was a crossing of cultures, of lifestyles, of ways of being and knowing... I would never be fully at home in India again or never fully at home in America” (Lakshmi, 2016, pp. 183-184). The move to New York left her confused regarding her identity as the world that she knew and grew up in was taken from her when she left New Delhi for New York to reunite with her mother.

Commenting on her status as an outsider and her difficulty with adjusting to the American lifestyle and culture, she writes that "I could only hope to survive if I made [the American] identity mine. And when I returned "home," to India, I would be an outsider there, too, because I had tasted the West" (Lakshmi, 2016, p. 190). Lakshmi grew up with a vegetarian diet and did not eat meat until she came to the United States, a diet that she maintained for a very long time. Given that food plays a central in constructing cultural identities, reluctantly claiming the American identity also meant that she had to change the way she lived, her beliefs, and other aspects of her Indian culture: she had to make room for her American identity, which meant altering her lifestyle. She did not claim this identity because she identified as such, rather, it was a survival method. She did not want to claim another national identity, yet, the circumstancesshe spent most of her time and formative years in the United States and did not return to India permanently_-gave her few options. From her perspective, to solve the situation that she was in, 
she only saw two options: the first option meant that if she wanted to maintain her Indian lifestyle as much as possible, she would have to reject what was American to her. The second options meant finding a balance and compromise between both if she wanted to survive in this new environment, and she opted for the second option.

Moreover, she writes that she had always kept her "Eastern and Western lives compartmentalized" (Lakshmi, 2016, p. 223). What is visible here is Lakshmi's effort to intentionally keep those two lives separate and she did not try to reconcile them or exist within multiple cultural worlds, rather, she chose to exist in two distinct worlds. Reflecting on her life experiences as a multilingual and multicultural individual, she shares an anecdote regarding a very specific moment in her life when she started designing jewelry. Expanding on her work space, she rented an office, and wanted to bless it with an Indian blessing ceremony, and in her reflection, she asks:

Who would I have become if my mother and I had never immigrated to the States? My work in food, fashion, and jewelry was definitely a result of all my travels, of the commingling of cultural influences I got to experience because I'd always had one food in the East and one food in the West... It felt good to hear Sanskrit echo in that office. And it comforted me to bring the various aspects of my current life together with the deepest spiritual origins of where I had come from. (Lakshmi, 2016, p. 223).

What we see here is that she recognizes the importance of her multicultural identity and how it had influenced her work and career and that neither would not have been possible had she not "had one foot in the East and one foot in the West" (Lakshmi, 2016, p. 223). When she understood that it is possible for her to be both Indian and American at the same time, i.e. allowing her identity to change and adapt to various situations, did not change her sense of self. 
Evidently, it was not until later, as an adult, when she "felt a cohesiveness of being, a joining of my two very real identities" revealing that her perspective changed: she did not view her Indian and American identities as mutually exclusive (Lakshmi, 2016, p. 223).

\section{Summary of Part I}

This section brought to light the struggles of belonging to multiple cultural communities and spaces where the writers' identities were contested, highlighting the choices that they made when constructing and negotiating their identities. More specifically, the struggles concerned various processes of "othering" that the writers experienced, particularly the role of their physical features, their "non-American" names, as well as other markers of their perceived "unAmericanness," such as the lack of participation in what the writers viewed as typical American cultural practices, e.g. riding in a station wagon or consuming junk food.

Although the writers claimed certain identities and membership to certain social groups and communities, they were not always seen as full members. As Norton (2010) states, we must understand identities in relational terms as individuals are either subject of or subject to a set of relationship, illustrating an uneven power distribution among people. As marginalized members of society, the South Asian American writers were not in the position to validate and legitimize their own membership status, although they made attempts at moving away from their subordinate position by changing aspects of their identities. Moreover, the writers' attempt at resolving their identity struggles also highlights the social and interactional elements of identity construction that Norton (2000) and Wenger (1998) underscore: the identities are not qualities or traits, nor do they remain the same across time and space, such as the name changes. 
Moreover, certain identities that the writers claimed led to conflict as they did not fit into stereotypes: from the perspective of the established members, the identities options were seen as fixed, which did not allow for internal variation (e.g. Norton Perce, 1995; Rayaprol, 1997). For example, as an Indian Jew, Delman is not a typical American Jew due to her complexion, nor is she a typical Indian as she is not Muslim or Hindu. As such, her identity was contested because she did not fit into the stereotypical Indian or Jew, and as an American by birth, she did not fit into the picture of the average American as she was not white or Christian.

In addition, as Park (2012) and Pavlenko \& Blackledge (2004) assert, one’s identity construction is not linear and previously rejected identities can be re-claimed, evident when Lakshmi opted to change her name from Padma to Angie, then Angelique, before re-claiming her birth name, Padma. While this journey was condensed to fit into a few pages, in reality, this developed over several years.

Lastly, the writers' identity struggles were not only about what choices they could make to fit in and become part of American society. Indeed, the choices that the writers made when their identities were contested reflect how they made continuous attempts at reconciling their identities that were seen as incompatible by themselves and others. While they might not have been aware of it at the time, the choices that the writers made could be seen as attempts at finding ways of constructing hybrid identities that would enable them to exist in and belong to multiple cultural spaces and communities, and by extension, American society. What their narratives reveal, then, is their concern and struggle with how to make room for the American identity in their lives rather than becoming something new. 


\section{Part II: The construction of identities within the narratives}

In this section, Theme 2: Labels and self-identification, Theme 3: Positioning of self and others, and Theme 4: Linguistic identities are presented and discussed. I will address the discursive aspects of the narratives, specifically focusing on narrative techniques and rhetorical devices that the writers employ to construct their identities within the texts and how these devices are used to understand the spaces they exist in. In other words, I will discuss how the writers define and refer to themselves in their narratives, how they position themselves and others, and their linguistic identities.

\section{Theme 2: Labels and self-identification}

What is of interest in this section is how the writers label and identify themselves. By examining the use of racialized and ethnic labels in the writers' narratives, we can uncover the way that they construct their identities within the texts, how they view themselves in relation to others, and get a glimpse of how they structure and organize their worlds by using these terms.

Generally, each writer focused mainly on their ethnic identities_-frequently referring to themselves as Indian or Bangladeshi — and how aspects of these identities intersected and were at odds with the dominant American culture and identity. The writers first and foremost identified themselves through their ethnicity, regardless of how much or how little time they had spent in their native countries. For example, both Delman and Mediratta are second generation immigrants, but refer to themselves as Indian in their narratives. By making the active choice of identifying themselves through ethnic terms, they position themselves as outsiders who are different from the white American. 
Although the writers regularly refer to themselves using ethnic labels, such as Indian and Bangladeshi, they rarely used hyphenated terms, such as Indian American or Asian American. ${ }^{8}$ The overwhelming use of ethnic terms within the narratives - in contrast to other available terms - illuminates how they perceive themselves. On occasion, some writers were more precise with the terms, such as Lakshmi (2016): "Even as a young girl I could tell that the South Indian chutneys we ate on the streets of Chennai were more balanced and round than the jagged-edged northern ones we had eaten in Delhi” (p. 93). The regional distinction that Lakshmi makes illustrates the complicated nature of identities as regionality plays a large role in constructing one's Indian identity. On the other hand, the choice of discussing their ethnic identities overshadowed the other identities that they had assumed, such as their American identities. Even though the writers had found ways of reconciling their identities, not much was said regarding how they viewed themselves as Americans.

Moreover, whenever the writers used the term South Asian, it was used as a collective term to refer to large groups of people and not necessarily themselves, as that was achieved by using ethnic terms instead. In the same way, they would rarely refer to themselves as Asian, American, Asian American, or Indian American. As stated earlier, the label "Asian" is problematic as there is no clear consensus regarding who can be identified as such, not to mention the fact that the label "Asian" is especially tricky as it is often considered to define East Asians. For example, Lakshmi assumes the Asian identity, although she mainly defines and refers to herself as Indian. When discussing the birth of her daughter, she writes that "[w]e were all expecting a brown-eyed, tawny-skinned little thing with jet-black Asian hair to appear and instead, out came this pale white baby with blue eyes and downy light-brown hair” (p. 254). She

\footnotetext{
${ }^{8}$ Alexander, Asher, Delman, Lakshmi, and Mediratta are of Indian origin, while Bose is Bangladeshi.
} 
defines herself and her daughter as Asian but primarily defines herself as Indian. This is also evident when Mediratta discusses her invisibility in society, and especially in the educational setting: "I felt little connection with the handful of Asian students, who were mostly East Asian and culturally quite different from me" (Mediratta, 1999, p. 81). While she positions herself as Asian here, the internal division that exist is also evident as she implicitly states that not all Asians are the same. Adding another layer of complexity to her identity, she also claims a hyphenated identity and refers to herself Indian American:

Later, in college, I began to take the idea of my own visibility more seriously, and consequently, to understand my status as "not-white" much more profoundly... I developed a political identity as a woman and defined my cultural identity as an Indian American” (Mediratta, 1999, p. 81).

Lastly, what is interesting is how the writers rarely referred to themselves as American as this label was reserved to those whose identities were not contested and those who were already part of mainstream society. For the most part, the writers would use marked terms when referring to themselves, such as Indian, South Asian, or Indian American, while those who were not marginalized were referred to simply as American. Thus, using these marked terms, the writers automatically position themselves as outsiders - whether this was a conscious choice or not is unclear-which we will see in the following section regarding the way they position themselves and others within the narratives.

\section{Theme 3: Positioning of self and others}

This sections looks more closely at how the writers use other means to construct their identities in the texts, specifically how they position themselves in relation to others. In addition 
to using ethnic labels to define themselves, the writers also employed other techniques to construct their identities besides using ethnic labels and other terms based on race and ethnicity. For example, Lakshmi positions herself as an outsider and different from the average white American when reflecting on her initial move to New York City as a child: "In New York I even heard many Indian languages spoken, including Tamil. I never felt like an outsider. Or at least when I did, I knew I was in the company of many, many other outsiders" (Lakshmi, 2016, p. 109). Despite the fact that she describes herself as an outsider, the feeling of alienation is what connects her to other people. In an anecdote regarding her walk to school, she notes that:

I’d pass Filipinos and Peruvians, Barbadians and Chinese, Puerto Ricans and African Americans and Middle Easterners. Even some of the white faces I saw were minorities, I learned, because they were Polish or had menorahs instead of Christmas trees. We were different from one another — we spoke different languages, ate different foods, went home to see our families in different far-flung countries - but we were alike in our differences. In that respect, New York City didn't feel that much different from India. (Lakshmi, 2016, p. 109).

What is clear from the previous quotes is that she aligns herself with other immigrants, thus, positioning herself as an immigrant with little connection with the white American. More specifically, she identifies with other immigrants who do not fit into the stereotypical image of the average American, and implicitly, as a person of color. In the quote, she describes those who had recently migrated to the United States who were still connected to their home countries. Additionally, menorahs are seen as marked as opposed to Christmas trees, painting a picture of the average American family as white and Christian. This highlights the diversity that exist internally among immigrant populations, but also their differences in relation to the stereotypical 
American. While she states that she is able to exist in both cultural spaces-Indian and American-she does not specify in what ways she feels American, as much of her narrative is about the conflicts that emerge from the friction between the cultural worlds that she belongs to.

On the other hand, when describing how Americans perceive Indians, Lakshmi points out that her Indian identity, particularly her skin color: "signaled third-world slums as seen in Indiana Jones movies, malaria, hot curry and "stinky" food, and strange bright clothing —a caricature of India and Indians" (Lakshmi, 2016, p. 105). What we can see in this quote is that she uses a range of symbols, e.g. malaria and hot curry, which create a stereotypical image of India, its people, and its culture. These associations have become fixed over time and do not produce an accurate image of India, and instead, India is portrayed in a negative light. She also does not use the word sari, which reinforces the limited awareness that Americans have-from Lakshmi's perspective_-regarding Indian culture. Lakshmi’s quote highlights the limited awareness of Indian culture that exists in the United States, and this stereotypical view manufactured a false Indian identity that was projected onto her.

Unlike Lakshmi, Delman is a second generation immigrant, but she does not explicitly refer to herself as American in her narrative and mostly describes herself as an Indian Jew. She positions herself and her family as outsiders, and highlights aspects of her life that, in her mind, are not American and cultural practices that typical Americans engage in. This is most noticeable when she discusses several objects and cultural practices that she associates with being American, such as station wagons, fast food, pop culture, going to the mall, and eating junk food. As these objects and cultural practices were not a significant part of her life, they took on an emblematic role and represented the "Americanness" that she was excluded from, making her life very different from that of her classmates. Unlike her classmates, Delman was not very 
knowledgeable about pop culture or the latest trends in music and fashion. This outsider position that Delman assumes, or inhabits, can be seen in the following quote as well:

I might have made up for what I was missing if not through television, which was regulated, then with a steady diet off the modern big screen. But going to the movies as a family was an expensive outing, so we rarely did it. Also there were very few movies my parents deemed appropriate for children. We saw a few drive-ins. And E.T. and The Song of the South... But aside from these, the glamour of film was foreign to me... (Delman, 2002, pp. 109-110).

In this quote, she positions herself as someone with an unprivileged background—her family had little money unlike her peers — and that her parents heavily regulated television watching and movies in terms of time and contents, which her classmates' parents did not. Although she grew up in the United States, the cultural practices of the average American youth were foreign to her, although she was born and raised in the United States. In other words, Delman's life and identities are in opposition to those of her classmates' and this illuminates her struggle with existing in the Jewish and Indian communities, but also within the bigger discourse of "Americanness" that she had little first-hand experience with.

Delman's way of resolving, and resisting her position as an outsider, was to find a way to access and participate in the cultural practices that were absent from her own life. One way of gaining access to these cultural practices was to socialize with her classmates at their birthday parties, which provided her with a peek into the life that she had only witnessed onscreen: At their parties, we ate junk food and looked through stacks of rented videos about college boys or rich Manhattan living beautiful ladies... We rummaged through the 
different pizza boxes... selecting drippy slices to sprinkle with red pepper and then consume. (Delman, 2002, p. 110).

Delman positions her classmates as mainstream American teenagers who were allowed to engage in typical American activities, unlike herself: she takes on the role of a newcomer who is learning about cultural practices of a foreign culture. Her own attempt at engaging in these activities is seen in the following quote when she plans her birthday party:

I had given [my mother] a much-considered list of the foods I wanted... But when she returned, she had bags and bags of the cheap generic snacks. Where were the flashy, scripted, famous brand names I had expected from the commercials? (Delman, 2002, pp. 111-112).

As Delman's parents struggled financially during this time, this restricted her even more as she could not live the life that her classmates did, and the image of "Americanness" that she had been exposed to through the media did not match up with her own life and reality. When describing the moment when the food is served at her party—macaroni and cheese as opposed to pizza - the way she positions herself and her classmates illuminates the distinct worlds that they occupy:

I saw [my classmates] exchange looks. This was not birthday party food. They could pull a box of macaroni-and-cheese from their loaded pantries at any old time. To me, because we never ate either macaroni-and-cheese or pizza, both were equally exotic. (Delman, 2002, p. 114).

These moments highlight how Delman positions herself and others around her: she is an outsider who tries to participate in cultural practices that are unfamiliar to her, but her lack of knowledge and understanding of the "American" practices and behaviors highlight her "otherness." 
Not unlike Delman, Mediratta, who is also a second generation American, expressed some confusion regarding her identity: 'I'm an 'ABCD'—an American Born Confused Desi (a Hindi expression for Indian.)" and she asks herself "What does it mean to be Indian? Can I choose to be both Indian and American? Is this choice mine to make?" (Mediratta, 1999, p. 84). She notes that when she went to teach in India for two years, it felt like home, even though she was born and raised in the United States and had little knowledge of her ancestry and had not developed fluency in any Indian language. Although she positions herself as Indian, she writes that there is some confusion regarding her identity and how she sees herself. On the other hand, she states that during her time in India, she became:

...conscious for the first time of how truly American I am-especially as a woman. I found myself alternately accepting and rebelling against what was expected of me... I was too dark, too thin, too independent, and too outspoken. In the end, how I lived in India exemplifies the many contradictions I felt about being there: feeling like a stranger in my supposed homeland, being a witness to a culture that is both mine and not mine. (Mediratta, 1999, p. 84).

The way that Mediratta positions herself is interesting as she positions herself as both American and Indian, depending on the context and from which perspective she views her own identities. In a way, she positions herself as an inside outsider — she feels at home in both cultural worlds, but at the same time, simultaneously feeling a connection and a disconnection from the cultural spaces that she inhabits. There is some tension that emerges from existing in one space as she claims two identities that are contradictory in some ways:

...I can't be Indian because I don't "sound Indian." In fact, a white man recently told me that I can't be a person of color because I don't sound like one. Americans in general 
seem to have difficulty accepting complexity and ambiguity. I'm either Indian or

American, white or black...I can't be both and neither. (Mediratta, 1999, p. 86).

As this quote shows, her perception of herself as a person of color directly clashes with the way the "white man" views her, claiming that having a non-mainstream American accent is what marks people of color. Further, she uses "American" to refer to mainstream society, which she is not part of, although she claims that particular identity. As shown earlier in Part I, Bose had a similar experience where one of her friends explained that he saw her as "white" as she was "accent-free" and fully assimilated. What is interesting here is that the way a person of color is constructed is not only based on skin color alone. One must also speak in a certain way, most likely in a foreign or non-standard manner, as well as engaging in practices and holding values that are perceived to be non-American.

This section has highlighted the ways in which the writers' position their race and ethnicity, and how they are positioned in their narratives. As the snapshots illustrate, the writers often positioned themselves as subordinate by illuminating what separated them from the average American, making linguistic choices that constructed them as outsiders and foreigners in the spaces that they occupied.

\section{Theme 4: Linguistic identities}

The memoirs and narratives were written in English with an English-speaking audience in mind as they were published in the United States, however, some of the writers did not strictly adhere to English-only in their narratives. This section is concerned with how the writers' multilingual and multicultural identities bleed into their writing and how their linguistic choices aid them in constructing their identities within their narratives. In other words, as most of the 
writers are bi-or multilingual, some of them—particularly Lakshmi and to some extent, Alexander-opted to incorporate their native languages ${ }^{9}$ into their narratives.

The use of their native languages provides us with an interesting glimpse into the minds of bi- or multilinguals, and in turn, how these linguistic and rhetorical choices simultaneously construct their identities in the narratives. However, we will see that the writers' linguistic identities were not unproblematic. Just like with other aspects of their identities, they also expressed a difficulty in reconciling their linguistic identities.

Alexander, questioning how she can reconcile her multiple identities and experiences, expresses confusion regarding her multilingual identity:

And what of all the languages compacted in my brain: Malayalam, my mother tongue, the language of first speech; Hindi, which I learnt as a child; Arabic from my years in the Sudan — odd shards of survive; French; English? How would I map all this in a book of days? (Alexander, 2003, p. 1).

Alexander's relationship with the languages that she knows is conflicting as each language has a different meaning and significance to her, and she acquired them at different periods in her life for various reasons. Her relationship with English is complicated as she grew up speaking Indian English rather than an Inner Circle variety, such as British English:

Over and over [my tutor] made me say: “duck," “duck," “pluck," “pluck, "milk," "milk, "silk," "silk." It was hard for her. I pouted, I fidgeted under the table... It was a ruinous waste of time but she persisted. I was all wrong, I knew it. And I felt quite ashamed. The trouble was, I knew the words already but in a different way. And she tried her best to

\footnotetext{
${ }^{9}$ While a discussion of what constitutes a native or first language, these will be used interchangeably to refer to the first language that the writers acquired as children.
} 
polish out my Indian English and replace it with the right model. From her point of view she did a good job. (Alexander, 2003, p. 112).

First of all, the quote sheds light on Alexander's negative experience and complicated relationship with the (re)-learning of the English language, revealing subordinating language ideologies and tension between varieties of English that stems from the notion of the existence of a Standard English, supposedly Received Pronunciation (RP). As we can see, the tutor is trying to replace Alexander's Indian English with a "correct" English variety. Consequently, Alexander's position as a legitimate speaker of English was challenged: she already knew the words but in a different way, which was not accepted as her tutor-though not necessarily her fault - attempted to correct Alexander by encouraging her to replace her variety with standard British English. Alexander's subordinated position was reinforced as she was a young student and had little agency to resist or reject the position that she was in, although her way of doing so was to stall.

Likewise, Asher also describes the friction between varieties of English—Indian English and American English — and addresses the questions of who is a legitimate speaker of English, and the issue of ownership of language. Regarding her linguistic identity, people have been confused about what languages she speaks, noting that people have asked her if she speaks Spanish. In other cases, people comment her on her ability to speak English and her accent, which is perceived as British, and not Indian. From her anecdote, the people who shared such comments with her reveal a skewed view of what is considered "correct" English and how Inner Circle varieties are the standard by which other varieties are measured, which further perpetuates the notion that there are legitimate and illegitimate varieties of English and that certain groups of people "own" it as if it were their property. Moreover, her anecdote also reveals a standard 
language ideology that promotes a homogenous variety of English that is maintained by dominant institutions, e.g. education, which at the same time, marginalizes and de-legitimizes other varieties, such as those that are spoken in Outer and Expanding Circle countries. In Alexander's case, her knowledge of Indian English was de-valued and de-legitimized as it was not see as proper English.

In a similar way, Lakshmi also expresses conflicting feelings regarding her linguistic identities, but she does not elaborate on how this shaped her relationship with Tamil, with her peers, the Indian community, and Indian Americans, nor does she provide details about how or if she managed to maintain or develop her first language. However, she explains that, as a child, she shuttled between India and the United States, which left her "perpetually confused and feeling like an outsider" (Lakshmi, 2016, p. 72). She mentions how she was unable to adhere to the correct spelling conventions, as she would mix them up. For example, in the United States she would write "colour" instead of "color" (Lakshmi, 2016, p. 72). Besides being exposed to a number of varieties of English, she was also surrounded by multiple languages:

I grew up speaking Tamil, the language of my ethnicity; Hindi, the national language but also the language of Delhi; and English. Others in my family added Malayalam, the language of Kerala, my ancestral home, to that list. "Please" and "okay" were in English and bookended many bursts of speech. "Please—someone might begin, then switch to Hindi-could you make some chai for me?” Then, without skipping a beat, she might continue in Tamil, "I'm really craving it" — then back to English—_Okay?" Certain words were just better in one language than another. (Lakshmi, 2016, pp. 315-316).

As the quote illustrates, Lakshmi existed in multiple overlapping linguistic spaces, evident by the code-switching that she was surrounded by. 
Since Lakshmi left India as a child and did not complete her education in India, she was unable to develop her literacy skills in her native language, Tamil. In middle school, English was the medium of instruction, and she notes that "I spoke Tamil more or less as well as my peers, but because I'd left India at age four, I couldn't read or write it” (Lakshmi, 2016, pp. 71-72).

Unlike Lakshmi, Bose had the opportunity to develop reading and writing skills in Bengali, as she enrolled in school in Bangladesh. In addition, her parents made efforts in maintaining their home language, but that " $[\mathrm{m}] \mathrm{y}$ younger sister and I would have preferred to watch cartoons on television, but we are now grateful for their decision. If we had not learned Bengali, we would not have been able to communicate with our relatives (Bose, 1999, p. 123). Looking more specifically at how fragments of their multilingual selves are found within their narratives, some of the writers commonly incorporated words from their native languages, which can be seen as a way to construct their multilingual and multicultural identities. By allowing their linguistic identities to become part of their narrative is another way of constructing their multicultural and multilingual identities within the text, and in way, makes that linguistic repertoire visible. Rather than separating and compartmentalizing them, the translingual choices that they make can be seen as a way for the writers to make sense of — and also construct - their linguistic identities.

Out of the six writers, Lakshmi was the one who incorporated non-English words the most and regularly throughout her narrative. She commonly used Hindi and Tamil words to refer to various foods, everyday objects, or other aspects of Indian culture:

My grandfather would occasionally spring for fruit when a religious ceremony, or puja, took place in our home... In fact, even on religious holidays, when we needed a 
prasadam, or offering, he preferred a liquidy, sweet rice or noodle pudding called payasam. (pp. 64-65).

Moreover, "I never bothered to fish out my chapals (slippers) from the shoe closet..." (p. 75). Another example of everyday objects can be seen in the following quote: "Traditional old South Indian homes had swings called oonjuls in Tamil or julas in Hindi” (p. 251). By using words in

Hindi and Tamil rather than translating them, she reinforces her Indian identity by incorporating words in Hindi and Tamil. The use of these words could also be seen as her way of claiming her ethnic identity. Since the narrative was composed in English in an English-speaking context, these limitations are not entirely fixed: she has to maintain English throughout her narrative, but there is some flexibility that allow for these translingual practices to appear in her text.

What this section has shown is that although the narratives were written in English, the other aspects of the writers' linguistic identities were not separate from their narratives. Some of the writers have complicated relationships with the English language, with issues emerging from the tension that exists between what are seen as "correct" and "incorrect" varieties of English, such as Alexander's tutor attempting to erase her Indian English and replace it with British English. Some writers, mainly Lakshmi, incorporated a number of non-English words in her narrative. What this section shows, then, is that the relationship that multilinguals have with the languages that they know is not simple and problem-free.

\section{Summary of Part II}

The second part of this chapter has focused on the narratives themselves and the rhetorical devices that the writers used to construct their identities within the texts. From this analysis, three themes emerged: Theme 2 concerned the use of labels and self-identification, 
while Theme 3 was focused on how the writers positioned themselves in the narratives, and lastly, Theme 4 was about the writers' linguistic identities.

Within the narratives, the writers first and foremost identified themselves through the use of ethnic identity labels, i.e. Indian or Bangladeshi, as opposed to using hyphenated labels or referring to themselves as American. They rarely referred to themselves as Asian and did not discuss how they identified with the Asian identity. Nevertheless, the fact that they did use this label to refer to themselves challenges and complicates the idea of what it means to be Asian and Asian American even though there is no consensus regarding the definition of Asian and its use (e.g. Park, 2008; Lippi-Green, 2012; Lo, 2016).

When it comes to the way the writers position themselves in the narratives, they often position themselves as foreigners as they highlight aspects of their identities that they thought differentiated them from those who were part of mainstream society. The most notable example is Delman's anecdotes about how the cultural practices that she engaged in were not seen as American, and her attempts at participating and becoming part of mainstream American society included mimicking the behavior of her peers, such as going to the mall, eating fast food, throwing a birthday party, and learning about pop culture. In her reflection, she positions herself as an outsider looking in and despite being born and raised in the United States, many cultural practices were unfamiliar to her, and in a way, exotic.

As for their linguistic identities, the snapshots that were provided illustrate the complicated relationship between the writers, their first language(s), English, and additional languages. Especially Alexander's relationship with English reveals a tension between multiple English varieties that are spoken in the world, the inequality that exists, and how English 
speakers of Outer and Expanding Circle countries struggle for legitimacy (e.g. Canagarajah, 1999; Lippi-Green, 2012; Park, 2008).

\section{Chapter summary}

In this chapter, the analysis of the memoirs and short narratives have shown that the identity construction and negotiation of these South Asian American writers was non-linear and that they used a variety of methods to resolve their identity struggles with varying degrees of success. For example, the two main methods the writers employed when attempting to resolve their identity struggles involved (1) changing aspects of their identities that were possible to change, such as their names, unlike their physical attributes, and (2) changing their behavior by engaging in cultural practices that were perceived to be American, such as consuming junk food and going to the mall.

Further, the writers also used other means of constructing their identities within the narratives through different linguistic choices and rhetorical devices, whether these choices were conscious or not. For example, they commonly used ethnic labels, e.g. Indian, to refer and define themselves, positioned themselves as foreigners and different from the average American, and their linguistic identities was visible in the text through the use of non-English words. In the next chapter, I will discuss what this analysis means for educators in multilingual and multicultural classrooms. 


\section{CHAPTER V: CONCLUSION}

\section{Summarizing the study and its goals}

As the student population in American classrooms have shifted considerably within the last decade, the presence of minorities in the classrooms is more prevalent now than ever: the National Center for Educational Statistics (2017) projects that Hispanic, Black, Asian or Pacific Islander students will make up the majority in K-12 classrooms by 2017. In such a multicultural society, current and future educators will have a great number of students with different educational backgrounds and needs, and these students will bring a variety of linguistic and cultural resources into the classroom. Therefore, understanding what types of adjustment issues or challenges that multilingual students might experience becomes crucial.

Most notably, the Asian population has increased more than any other minority group in the United States—-from 10.2 million to 14.7 million—and the linguistic landscape has also changed, particularly South Asian languages have increased significantly (U.S. Census Bureau, 2012, 2013). However, the statistics do not tell us much about who these individuals are, what life experiences, and knowledge they bring into the classroom. The statistics also fail to show the linguistic and cultural diversity that exists within the Asian population, creating a homogenous “Asian" identity grounded in stereotypes (e.g. Kumaravadivelu, 2008; Lo \& Reyes, 2009). Due to these demographic and linguistic changes, it is critical and imperative to investigate the sociocultural and linguistic profiles of these individuals.

Despite making up a large part of the American population, the Asian population, especially the South Asian population, has not been studied to the same extent as other minority groups (Lo \& Reyes, 2009). Therefore, the aim of the present study was to investigate the lived experiences of South Asian Americans and highlight the internal differences that exist within this 
particular group, and by extension, the differences that exist within the Asian population. The study also seeks to challenge the "Asian" label as such false mislabeling can affect students' learning and classroom practices negatively. Therefore, it is imperative for us to understand what linguistic and cultural resources these students-including adult multilinguals who went through schooling in the United States-bring into the classroom, but also what type of struggles they might encounter, specifically identity struggles and the negotiation of their identities in the educational and familial domains. In order to address these topics, the following research questions were formed:

1. What identity struggles do South Asian American writers experience in various spaces and how are these struggles resolved and addressed in their written narratives?

2. What kind of themes and commonalities emerge in the South Asian American writers' narratives regarding their identity negotiation?

3. How do South Asian American writers identify with or label "Asian" as they refer to their ethnic identities?

To find the answers to these questions, narrative inquiry was employed. Further, a corpus that consisted of published life writing was created, which included memoirs and short narratives written by South Asian Americans, including first generation, 1.5 generation, and second generation immigrants. These narratives were then analyzed in order to find common themes regarding South Asian American authors' identity struggles and how these struggles intersected with race, culture, and language. While common themes emerged, the purpose was not to generalize the South Asian American experience. Instead, the goal was to highlight the identity negotiations that multilinguals experience and their attempts at resolving those struggles. 
Another aim of this thesis is to explore other research methods to investigate multilingual identities. By looking at multilinguals' identity negotiation by utilizing published life writing also fills a gap in current research as data is commonly collected through interviews and ethnographic observations. Since life writing was previously seen as anecdotal and erroneous (e.g. Kanno, 2003; Pavlenko \& Lantolf, 2000), the shift from viewing it as less factual and incorrect has opened up for more possibilities for identity research. Narratives allow (multilingual) individuals to share their lived experiences and make their voices heard, while giving writers the agency to share their experiences on their own terms (e.g. Nieto, 2004). In this particular case, then narratives that were chosen were composed by those who are generally not visible to mainstream culture. In addition, by choosing to use published life writing as the primary source, I recognize that human experience is messy and in many ways, unquantifiable, which aligns with post-structuralist approach of looking at identity, i.e. it is ever-changing, contradictory, and multifaceted.

Besides focusing on the contents of the narrative, the data analysis also focused on the discourse and rhetorical devices that the writers used, and I examined how the writers (1) used labels and identified themselves, (2) positioned themselves within the narratives, and (3) their linguistic identities. Moreover, by focusing on the writers' experiences in the educational and familial domains, and everyday life, it was possible to shed light on the identity struggles and negotiation processes that they underwent in those specific spaces, with the purpose of providing educators with a glimpse of what multicultural and multilingual individuals might struggle with in the classroom, at home, and in everyday life.

With this study, I have expanded identity research on multicultural and multilingual individuals by adopting narrative inquiry as a research tool. While previous research has 
commonly made use of other qualitative and quantitative methods, such as interviews, surveys, and ethnographic observations, narrative inquiry has not been applied in identity research to the same extent as it has been considered anecdotal, less factual and erroneous (Pavlenko, 2002). However, various scholars, such as Bell (2002), Kanno (2003), and Pavlenko (2002), maintain that the use of narratives can provide us with an understanding of how multilinguals make sense of their lived experiences and how they themselves understand their own identity construction and identity negotiation processes.

In this final chapter, I will first revisit and summarize the answers to each of the research questions. Second, I will discuss the limitations of the current study and future research possibilities. The chapter will be concluded with some final comments on the use of narrative inquiry as a tool to explore multilingual identity construction and negotiation.

\section{Revisiting research question 1: Identity struggles}

The first research question that I asked sought to illuminate the South Asian American writers' identity struggles as multicultural and multilingual individuals in the United States and how they attempted to resolve their identity struggles. I was specifically interested in how they addressed conflicts that emerged through interactions with people at school, such as their peers, at home with their family members, and in their everyday lives.

Overall, the identity struggles that the writers experienced emerged in daily interactions in school (K-12 and higher education), at home, and everyday life. Even the writers who were part of the same generation had different experiences and different ways of resolving their identity struggles. For example, the feelings of in-betweenness and alienation from mainstream society were experienced by each of the writers to varying degrees and it was not necessarily a 
generational issue: Delman, a second generation Indian Jew, shared these feelings of alienation and disconnection with Lakshmi, a 1.5 generation immigrant. Further, many of the writers noted that because they grew up in predominantly white areas, they were outsiders as the average American was constructed as white and Christian. As the writers did not see themselves as part of the dominant group, they struggled with becoming part of mainstream society as aspects of their identities, such as their names and their physical attributes, marked them as different. In other words, their physical attributes marked them as "others" and marked their marginalized position in society. The issue of "othering" - mainly addressed by Lakshmi, Delman, Bose, and to a lesser extent by Mediratta and Alexander-made it difficult and sometimes prevented them from fitting in. They attempted to resolve these struggles in different ways, in some cases going as far as changing parts of their identities, such as their names, in order to have their membership "validated" and "approved" by the members of the dominant group and communities that they wanted to belong to.

Moreover, conflict and tension emerged in the familial domain, as some of the writers' values and cultural practices clashed with that of their parents and other family members. In other cases, the familial values and practices that the writers had embraced did not align with that of mainstream society. While the writers attempted to change parts of their identities, such as their names, in some other instances, the writers attempted to change their behavior by engaging in what was perceived to be typical American activities and cultural practices, such as going to the mall, eating fast food, and riding in a station wagon. As these cultural activities were seen as American, the writers, especially Delman, Lakshmi, and Bose, attempted to engage in "nonethnic" practices in order to fit in, but they were not always successful. One example is how Delman made attempts at becoming more like her peers by going to the mall—which her parents 
reluctantly allowed - but instead of going with friends and bonding with them, she went alone, and did not know what to do while at the mall.

As we can see, the writers struggled with several aspects of their identities that mainly concerned belonging and fighting the feelings of disconnection and in-betweeness. The writers attempted to resolve these struggles in different ways, mainly by changing the parts of their identities that were possible to change, such as their names. They also changed the way they lived their lives and their behavior in spaces where their identities were contested, such as engaging in cultural practices that were seen as typically American, in order to fit in.

Mispronouncing a name or imposing an "easier" version or a nickname for a student with a nonmainstream name diminishes their agency and devalues their identity, and also opens up a discussion about the relationship between naming rights, language ideologies, and cultural assimilation. As seen in Bucholtz (2016) and Taylor-Mendes (2003), names are inseparable from one's identity and a place for identity negotiation and construction: a name can be taken, imposed, rejected, or altered by the bearer of the name or others. That being said, in some other cases, as seen in Edwards (2006), the Chinese students opted for western names as this choice allowed them to take on a different identity that separated their personal, professional, and academic identities. Moreover, similar to the students in Bucholtz (2009) and Quach et al. (2008), the writers changed their behavior and cultural practices in attempts to fit in. One of the students in Bucholtz (2009) tried to fit in by speaking African American Vernacular English (AAVE) because it allowed her to interact with her peers and marked her belonging to that particular social group. Similarly, students in Quach et al. (2008) purposely chose to befriend White students rather than other minority groups, and some even altered their physical appearance in order to fit in. 
Previous research has shown that those who are in a marginalized position make choices, whether these are linguistic or non-linguistic choices, to fit into mainstream society and that there is a fixed image of what Americans look like, what cultural practices Americans engage in, and what it means to be (un)American. In this particular case, the writers constantly engaged in negotiation processes with people in their lives to (co-)construct their identities that were contested. What is visible here is the tension that emerged between their perception of themselves and the way others perceived them. Not only does the conflict emerge from interactions with others, the writers also struggled internally with making their contradictory identities co-exist (e.g. Clark, 2013; Norton, 2000; Tajfel, 1982). Regardless if they were first generation, 1.5 generation, or second generation immigrants or if they thought of themselves as American, to be accepted as a full member of American society required more than being born in the United States.

\section{Revisiting research question 2: Themes and commonalities}

This research question was developed to investigate what kind of overarching themes emerged from the writers' narratives regarding their identity negotiation. From this analysis, four themes emerged: (1) "othering," which included issues linked to skin color, names and identity, and being (un)American, (2) labels and self-identification, (3) positioning of self and others, and (4) linguistic identities.

In Chapter IV Part I, I addressed the issues of "othering" that the writers underwent. As stated previously, the identity negotiation that they experienced in daily interaction emerged from the conflicting ways the writers perceived themselves and the way others viewed them. It was also an internal struggle as finding ways of reconciling their contradictory identities was not 
always successful, as members of the communities to which they claimed membership did not view their identities as fluid and flexible: there were set ideas of what a "real" Indian or American should be like. In the narratives, several aspects of the writers' identities marked them as "others." For starters, the writers' physical characteristics, specifically their skin color, was a source of conflict, which they developed a complicated relationship with. For Delman, and Lakshmi, their skin color was a permanent marker of their "otherness" and reminded them of how they were different from the white American. Another marker of the writers" "otherness" concerned cultural practices. Not only does one have to share the same or similar physical attributes to fit in, one must also be able to participate in typical "American" activities. In this case, this meant going to the mall with friends or consuming fast food. Third, their names, specifically addressed by Lakshmi, Alexander, and Mediratta, marked their "otherness" and made it difficult for them to identify with their names or fully embrace the identities that were attached to their names, which prompted them to modify or replace their names altogether, a process that went on for a long time.

Chapter IV Part II focused on the discourse itself, and concerned Theme 2: Labels and self-identification, Theme 3: Positioning of self and others, and Theme 4: Linguistic identities. Regarding Theme 2, the writers primarily used ethnic labels when referring to themselves. Instead of using hyphenated labels, they would use Indian or Bangladeshi. By doing that, they highlighted aspects of their identities that were in opposition to the average American who was defined as white and Christian. By choosing to define themselves by their ethnicity, the writers positioned themselves as outsiders (Theme 3 ) and not fully part of American society as they rarely referred to themselves as American. For example, Lakshmi saw herself as an immigrantforeign - and felt more at home in New York City among non-white and/or non-Christian 
Americans. Similarly, Delman positioned herself as an inside outsider: she learned, through observation and interaction with her peers, about American culture and what typical teenagers do. As an Indian Jew, she felt disconnected from both the Indian and Jewish communities, as Jews are stereotypically — or expected — to be white, while Indians are supposed to be Hindu or Muslim. The last theme, Theme 4, concerned the writers' relationship with language and their linguistic identities. Some of the writers explicitly discussed their complicated relationship with the English language that mainly dealt with their position as (il)legitimate speakers of English and by extension, questions regarding the ownership of English. Other aspects that were not explicitly discussed, but very much present in the narratives, was the blending of English and non-English words and expressions. In those instances, it was clear that the writers could not compartmentalize their multiple identities and separate them: by using non-English words, pieces of their multicultural and multilingual identities were merged with their "English" identity.

The themes that emerged from the writers' narratives can be seen as counternarratives that challenge prevailing ideas of a fixed and homogenous "Asian" identity, and even though the writers do not explicitly define or explain what Asian means to them, the choices that the writers' made regarding the use of labels challenge the fixed "Asian" identity and complicates the idea of what it means. Previous research shows that there is still confusion about who the term "Asian" refers to, and especially in the case of South Asians, there is no consensus regarding the use of "Asian" (e.g. Kumaravadivelu, 2008; Lippi-Green, 2012; Lo, 2016; Park, 2008). Although there is confusion regarding who "Asian" refers to, the writers' narratives show that the internal diversity that exists among ethnic groups often gets neglected or overlooked (e.g. Lo \& Reyes, 2009; Rayaprol, 1997). 
Additionally, the writers position themselves as foreigners and outsides in their narratives, and were also viewed as such by people who were part of their daily lives, such as their peers. At the same time, some of the writers were not seen as foreigners or outsiders, and instead, they were seen as fully assimilated due to the absence of a foreign accent. These two contradictory ways of positioning people of Asian origin further echo what other scholars have maintained: Asians are seen as either perpetual foreigners or honorary whites (e.g. Lo, 2016; Lo \& Reyes, 2009; Wu, 2002). Regardless of the time of their arrival, the writers struggled with these imposed identities, and from a larger context, we can connect this to a colorblind ideology and the one-sided way of looking at racism that erases the lived experiences of these writers.

Lastly, some of the writers' relationship with English highlight the tension between Inner Circle and Outer Circle varieties of English, specifically issues about who is seen as an (il)legitimate speaker of English and questions regarding the ownership of English. Moreover, these issues regarding legitimacy and ownership are connected to language ideologies that support Standard English, or Inner Circle varieties, and these beliefs are upheld and disseminated through various institutions (Lippi-Green, 2012). For example, Alexander's status as a legitimate speaker of Indian English is questioned when her British tutor makes efforts to alter the way she speaks as Indian English was not perceived to be a legitimate variety, reflecting the power struggle that exists between varieties of English and how students and educators struggle for legitimacy if they do not speak an Inner Circle variety of English (e.g. Amin, 1997; Canagarajah, 1999; Matsuda, 2003; Motha, Jain, and Teccle, 2012; Seloni, 2012). 


\section{Revisiting research question 3: Identifying with the "Asian" identity}

As previous studies have shown, there is some uncertainty regarding who is —or can — be defined as Asian. Whereas East Asians are typically seen as "Asians," the label is more problematic when used to describe other groups of people from Asian countries, such as South Asians (e.g. Kurien, 2005; Lippi-Green, 2012; Lo, 2016; Morning, 2001; Park, 2008). What is of interest is the writers' use of labels and self-identification and the range of terms that they use to define themselves. Although they mainly use ethnic terms, such as Indian and Bangladeshi, several hyphenated terms appear but are used to a lesser extent, such as Indian American, Asian (American), or South Asian (American). In a way, it appears that the writers assume an "Asian" identity, but they do not challenge the term, nor do they elaborate on how they define it, or explain what it means to them. Nevertheless, their narratives can still be viewed as counternarratives that challenge the perceived homogenous Asian identity and by extension, the perceived stability of identities, in particular racial, ethnic, and national identities.

In the narratives, the writers mainly used ethnic terms to refer to themselves, and rarely used or discussed the term "Asian" — or other non-ethnic terms — and what it means to them. Although the writers did not explicitly address or challenge the perceived homogenous Asian identity, their lived experiences do complicate the definition of "Asian" and what the term entails. In some cases, the "Asian" identity was assumed as the short narratives were part of two different collections of narratives written by Asian Americans, addressing their ethnic identities, and Asian women scholars in higher education. For example, in one of the short narratives, Mediratta, referred to when she discussed her educational experience: although there were Asian students at her school, they were mainly of East Asian descent, and she stated that she did not relate to them. Although she assumed the "Asian" identity, she did not specifically discuss how 
she related to it, but we can see that she differentiates between various Asian populations, reinforcing the internal diversity that exists. While she might have felt a connection to other Asian people, such as East Asians, she appears to have a stronger connection with South Asians. This is further exemplified in Lakshmi's memoir when she discusses the birth of her daughter and is surprised when she realizes that her daughter did not have "jet-black Asian hair" (Lakshmi, 2016, p. 254). In this scenario, she refers to her daughter — and herself — as Asian, but primarily defines herself as Indian throughout her memoir.

What is interesting is that while the writers do consider themselves "Asian," at the same time, they often more closely identify as being South Asian. It is not explained in the narratives what makes them define themselves as Asians and we do not know the reasoning behind their choice of terms: is it because of culture? Language? Or merely the fact that South Asian countries are located in Asia? Although they do not directly address or challenge the term "Asian," their narratives act as counternarrative and complicate the way we see racial, ethnic, and national identities.

\section{Limitations of the study and future research}

After concluding this study, it is important to acknowledge that the findings of this study are far from comprehensive and complete and might not fully map out the identity construction and negotiation processes that the writers went through. As such, a thorough assessment of the writers' sociocultural and linguistic profiles was not possible to complete as many identity markers were omitted from the analysis. As the scope of this study was limited to the investigation of only a few identity markers, I realize that many other aspects that shape multilingual identities were left out that could have played important parts in the writers' identity 
negotiation and construction. However, narrative inquiry and exploring published life writing have opened up for a wealth of information regarding the construction of multilingual identities. For future research, a larger sample of narratives written by both male and female writers, as well as the inclusion of other identity markers, e.g. class, and focus on other spaces, e.g. the work place, could provide us with a more complete profile of South Asian Americans.

Another change for future research could be made to the data collection process and research methodology. The narratives that were used for this thesis came from published life writing, but future research could benefit from extending the range of life writing, and include unpublished or non-print narratives, such as narratives from blogs or written by students or other bicultural or bilingual individuals. In addition, the use of narrative inquiry could also be combined with other research methods, such as interviews and ethnographic observations in order to gain a more comprehensive and in-depth understanding of how the writers actually negotiate their identities in various spaces.

\section{Concluding comments}

With this study, I aimed to broaden the types of methodologies that are used to research multilingual identities by employing narrative inquiry and using published life writing as my primary source of data. The shift from viewing narratives as anecdotal and erroneous to viewing them as legitimate knowledge opens up numerous possibilities for identity research. Particularly with the technological developments in this digital age, non-print narratives, such as blogs, are waiting to be explored. As I have shown with this study, the use of narrative inquiry allows us to look at individual experiences that can function as counternarratives to break stereotypes instead of perpetuating them. Further, investigating narratives also provides us with the identity 
construction and negotiation at the textual level and not only through content-analysis, allowing the complexities connected to language and identity to emerge and be explored.

Additionally, the findings challenge the seemingly fixed identity categories, as well as shed light on some of the issues that might arise in a culturally and linguistically diverse contexts, such as work places or classrooms. As each individual's experiences will be different, regardless if their country of origin is the same, how they react to cultural and linguistic conflicts will be different: there are nuances and subtleties that must be made visible. Indeed, complicating identity categories becomes even more critical in the current political climate and the age of anti-discrimination. Misconceptions and false portraits of certain groups of people persist and are spread through various media, making it even more urgent for counternarratives to surface and challenge those misconceptions. Particularly the voices of those who are commonly silenced by the dominant narratives should be brought to light.

Thus, as educators — and as members of a multicultural society — we must keep an open mind about our students' experiences and remember that although they might look the same and define themselves in certain ways, the identity labels do not tell us much about who they actually are, and all layers of their identities might not be visible. The findings of this study complicate our notion of identity even more and echoes results from previous research: we should view students' as individuals with agency and allow them to make their voices heard and show us who they are. In the classroom context, incorporating life writing assignments, such as blogs or letters, can give students the space to revisit their lived experiences but also allow instructors to get a glimpse of what their students might struggle with in order to understand multilingual identities. At the same time, revisiting their lived experiences and identity struggles could help the students understand themselves better. While this thesis aimed to investigate and shed light 
on the identity struggles of South Asian Americans, in a way, the exploration of other people's identity struggles allowed me to understand my own multilingual identity as well.

As this thesis began with a quote about identity struggles and the challenge in finding a balance between different and contradictory cultural worlds, I would like to conclude this thesis with a quote from Seloni (2016) that captures the never-ending journey of (re)-constructing one's multilingual identity:

Perhaps immigrant identity is like a weed. Despite their negative connotations, weeds can easily grow, spread in soil and adapt to diverse environments. They are adaptable, wild and tenacious. They have the capacity to evolve rapidly. Even if they are newcomers to their environments, you need to pull them strongly to detach them from newly found homes. Perhaps we are all a little like weeds ready to spread in different directions, growing strongly in different types of soils, building new homes and new roots. (p. 267). 


\section{REFERENCES}

Alexander, M. (2003). Fault lines: A memoir. New York, NY: The Feminist Press.

Alim, H. S. (2016). Introducing raciolinguistics: Racing language and languaging race in hyperracial times. In H. S. Alim, J. R. Rickford \& A. F. Ball (Eds.), Raciolinguistics: How language shapes our ideas about race (pp. 1-30). Oxford: Oxford University Press.

Amin, N. (1997). Race and the identity of the nonnative ESL teacher. TESOL Quarterly, 31, $580-583$

Asher, N. (2006). Brown in black and white: On being a South Asian woman academic. In G. Li \& G. H. Beckett (Eds.), "Strangers” of the academy: Asian women scholars in higher education (pp. 163-177). Sterling, VA: Stylus Publishing.

Bell, J. S. (2002). Narrative inquiry: More than just telling stories. TESOL Quarterly, 36, 207213.

Bose, M. J. (1999). Multiple identities. In P. G. Min \& R. Kim (Eds.), Struggle for ethnic identity: Narratives by Asian American professionals (pp. 120-129). Walnut Creek, CA: AltaMira Press.

Bucholtz, M. (2009). Styles and stereotypes: Laotian American girls' linguistic negotiation of identity. In A. Reyes \& A. Lo (Eds.), Beyond yellow English: Toward a linguistic anthropology of Asian Pacific Americans (pp. 21-42). Oxford: Oxford University Press.

Bucholtz, M. (2016). On being called out of one's name: Indexical bleaching as a technique of deracialization. In H. S. Alim, J. R. Rickford \& A. F. Ball (Eds.), Raciolinguistics: How language shapes our ideas about race (pp. 273-289). Oxford: Oxford University Press.

Canagarajah, S. A. (1999). Resisting linguistic imperialism in English teaching. Oxford: Oxford University Press. 
Center for Advanced Research on Language Acquisition (CARLA). (2014). What is culture? Retrieved from http://carla.umn.edu/culture/definitions.html

Clark, U. (2013). Language and identity in Englishes. New York, NY: Routledge.

Delman, C. (2002). Burnt bread and chutney: Growing up between cultures-A memoir of an Indian Jewish Girl. New York, NY: One World/Ballantine Books.

Edwards, R. (2006). What's in a name? Chinese learners and the practice of adopting 'English' names. Language, Culture and Curriculum, 19, 90-103.

Ferris, D. R., \& Hedgcock, J. S. (2014). Teaching L2 composition: Purpose, process, and practice. New York, NY: Routledge.

Hardy, B. (1968). Towards a poetics of fiction: Novel, 2, 5-14.

Hill, J. (2009). On using semiotic resources in a racist world: A commentary. In A. Reyes \& A. Lo (Eds.), Beyond yellow English: Toward a linguistic anthropology of Asian Pacific Americans (pp. 84-89). Oxford: Oxford University Press.

Inman, A. G. (2006). South Asian women: Identities and conflict. Cultural Diversity and Ethnic Minority Psychology, 12, 306-319.

Institute of International Education. (2016). International students: Leading places of origin. Retrieved from http://www.iie.org/Research-and-Publications/OpenDoors/Data/International-Students/Leading-Places-of-Origin\#.WKRoWPkrL6Q

Kottak, C. P. (2009). Anthropology: The exploration of human diversity. Boston, MA: McGraw Hill.

Kumaravadivelu, B. (2008). Cultural globalization and language education. New Haven, CT: Yale University Press. 
Kanno, Y. (2003). Negotiation bilingual and bicultural identities: Japanese returnees betwixt two worlds. Mahwah, NJ: Lawrence Erlbaum Associates.

Kubota, R., \& Lin, A. (2009). Race, culture, and identities in second language education: Introduction to research and practice. In R. Kubota \& A. Lin (Eds.), Race, culture, and identities in second language education: Exploring critically engaged practice (pp. 1-23). New York, NY: Routledge.

Kurien, P. A. (2005). Being young, brown, and Hindu: The identity struggles of secondgeneration Indian Americans. Journal of Contemporary Ethnography, 34, 434-469.

Lakshmi, P. (2016). Love, loss, and what we ate: A memoir. New York, NY: HarperCollins.

Lee, E. (2015). Doing culture, doing race: Everyday discourses of 'culture' and 'cultural difference' in the English as a second language classroom. Journal of Multilingual and Multicultural Development, 36, 80-93.

Lippi-Green, R. (2012). English with an accent: Language, ideology, and discrimination in the United States. New York, NY: Routledge.

Lo, A. (2016). "Suddenly faced with a Chinese village": The linguistic racialization of Asian Americans. In H. S. Alim, J. R. Rickford \& A. F. Ball (Eds.), Raciolinguistics: How language shapes our ideas about race (pp. 97-111). Oxford: Oxford University Press.

Lo, A., \& Reyes, A. (2009). Introduction: On yellow English and other perilous terms. In A. Reyes \& A. Lo (Eds.), Beyond yellow English: Toward a linguistic anthropology of Asian Pacific Americans (pp. 3-17). Oxford: Oxford University Press.

Matsuda, A. (2003). Incorporating World Englishes in teaching English as an international language. TESOL Quarterly, 37, 719-729. 
Markus, H. R., \& Moya, P. M. L. (2010). Doing race: An introduction. In H. R. Markus \& P. M. L. Moya (Eds.), Doing Race: 21 essays for the 21st century (pp. 1-102). New York, NY: W. W. Norton and Company.

Mediratta, K. (1999). How do you say your name? In P. G. Min \& R. Kim (Eds.), Struggle for ethnic identity: Narratives by Asian American professionals (pp. 77-86). Walnut Creek, CA: AltaMira Press.

Morning, A. (2001). The racial self-identification of South Asians in the United States. Journal of Ethnic Migration Studies, 27, 61-79.

Moran, P. (2001). Defining culture. In P. Moran (Ed.), Teaching culture: Perspectives in practice (pp. 23-47). Boston, MA: Heinle ELT.

Motha, S. (2006). Racializing ESOL teacher identities in U. S. K-12 public schools. TESOL Quarterly, 40, 495-518.

Motha, S., Jain, R., \& Teccle, T. (2012). Translinguistic identity-as-pedagogy: Implications for language teacher education. International Journal of Innovation in English Language Teaching, 1, 13-28.

National Center for Educational Statistics (NCES). (2017). Table 203.50: Enrollment and percentage distribution of enrollment in public elementary and secondary schools, by race/ethnicity and region: Selected years, fall 1995 through fall 2023. Retrieved from https://nces.ed.gov/programs/digest/d13/tables/dt13_203.50.asp

Nieto, S. (2004). Affirming diversity: The sociopolitical context of multicultural education. Boston, MA: Pearson.

Norton, B. (2000). Identity and language learning: Gender, ethnicity, and educational change. Harlow: Longman. 
Norton, B. (2010). Language and identity. In N. Hornberger \& S. Lee McKay (Eds.), Sociolinguistics and language education (pp. 349-369). Clevedon: Multilingual Matters LTD.

Norton Peirce, B. (1995). Social identity, investment, and language learning. TESOL Quarterly, 29, 9-31.

Park, J. Z. (2008). Second-generation Asian American pan-ethnic identity: Pluralized meanings of a racial label. Sociological Perspectives, 51, 541-561.

Park, G. (2009). "I listened to Korean society: I always heard that women should be this way...”: The negotiation and construction of gendered identities in claiming a dominant language and race in the United States. Journal of Language, Identity, and Education, 8, 174-190.

Park, G. (2012). "I am never afraid of being recognized as an NNES": One teacher's journey in claiming and embracing her nonnative speaker identity. TESOL Quarterly, 46, 127-151.

Pavlenko, A. (2002). Narrative study: Whose story is it, anyway? TESOL Quarterly, 36, 213218.

Pavlenko, A., \& Blackledge, A. (2004). Introduction: New theoretical approaches to the study of negotiation of identities in multilingual contexts. In A. Pavlenko \& A. Blackledge (Eds.), Negotiation of identities in multilingual contexts (pp. 1-33). Clevedon: Multilingual Matters LTD.

Pavlenko, A., \& Lantolf, J. P. (2000). Second language learning as participation and the (re)construction of selves. In J. P. Lantolf (Ed.), Sociocultural theory and second language learning (pp. 155-177). Oxford: Oxford University Press.

Pennycook, A. (2001). Critical applied linguistics: A critical introduction. Mahwah, NJ: Lawrence Erlbaum Associates. 
Pew Research Center. (2012, June 19). The rise of Asian Americans. Retrieved from http://www.pewsocialtrends.org/2012/06/19/the-rise-of-asian-americans/

Quach, L., Jo, J. O., \& Urrieta, L. (2009). Understanding the racialized identities of Asian students in predominantly white schools. In R. Kubota \& A. Lin (Eds.), Race, culture, and identities in second language education: Exploring critically engaged practice (pp. 118-137). New York, NY: Routledge.

Ramanathan, V. (2005). Situating the researcher in research texts: Dilemmas, questions, ethics, new directions. Journal of Language, Identity, and Education, 4, 291-293.

Rayaprol, A. (1997). Negotiating identities: Women in the Indian diaspora. Oxford: Oxford University Press.

Reyes, A. (2007). Language, identity, and stereotype among Southeast Asian American youth: The other Asian. Mahwah, NJ: Lawrence Erlbaum Associates.

Rubin, D. L. (1992). Nonlanguage factors affecting undergraduates' judgement of nonnative English-speaking teaching assistants. Research in Higher Education, 33, 511-531.

Seloni, L. (2012). Going beyond the native-nonnative English speaker divide in college courses: The role of nonnative English-speaking educators in promoting critical multiculturalism. Journal on Excellence in College Teaching, 23, 129-155.

Seloni, L. (2016). In search of an identity: An accidental immigrant's story of belonging and migration. In R. N. Bali (Ed.), "This is my new homeland”-Life stories of Turkish Jewish immigrants (pp. 247-267). Istanbul: Libra.

Starfield, S. (2015). First person pronoun: Negotiating identity in academic writing in English. In D. Djenar, A. Mahboob \& K. Cruickshank (Eds.), Language and identity across modes of communication (pp. 249-262). Berlin: De Gruyter Moton. 
Tajfel, H. (1982). Introduction. In H. Tajfel (Ed.), Social identity and intergroup relations (pp. 111). Cambridge: Cambridge University Press.

Taylor-Mendes, C. (2003). Our names. TESL Canada Journal, 21, 97-101.

United Nation Statistics Division. (2016). Composition of macro geographical (continental) regions, geographical sub-regions, and selected economic and other groupings. Retrieved from http://unstats.un.org/unsd/methods/m49/m49regin.htm

U.S. Census Bureau. (2000). Table DP-1. Profile of general demographic characteristics: 2000. Retrieved from http://censtats.census.gov/cgi-bin/pct/pctProfile.pl

U.S. Census Bureau. (2012). The Asian population: 2010. Retrieved from https://www.census.gov/prod/cen2010/briefs/c2010br-11.pdf

U.S. Census Bureau. (2013). Language use in the United States: 2011. Retrieved from https://www.census.gov/prod/2013pubs/acs-22.pdf

Wenger, E. (1998). Communities of practice: Learning, meaning, and identity. Cambridge: Cambridge University Press.

Wu, F. H. (2002). Yellow: Race in America beyond black and white. New York, NY: Basic Books.

Woolard, K. A. (1998). Introduction: Language ideology as a field of inquiry. In B. B. Schieffelin, K. A. Woolard \& P. V. Kroskrity (Eds.), Language ideologies: Practice and theory (pp. 3-47). Oxford: Oxford University Press. 